\begin{tabular}{|l|l|}
\hline $\begin{array}{l}\text { 2. To: (Receiving Organization) } \\
\text { Distribution }\end{array}$ & $\begin{array}{l}\text { 3. From: (Originating Organization) } \\
\text { TWRS Configuration Management }\end{array}$ \\
\hline 5. Proj./Prog./Dept./Div.: & $\begin{array}{l}\text { 6. Design Authority/ Design Agent/Cog. } \\
\text { Engr: }\end{array}$ \\
TWRS & J. M. Vann \\
\hline
\end{tabular}

8. Originator Remarks:

For approval and release.

4. Related EDT No.:

$N / A$

7. Purchase Order No.:

N/A

9. Equip./Component No.:

$N / A$

10. System/Bldg./Facility:

$\mathrm{N} / \mathrm{A}$

11. Receiver Remarks: 11A. Design Baseline Document? [] Yes [X] No

12. Major Assm. Dwg. No.:

$N / A$

13. Permit/Permit Application No.: $\mathrm{N} / \mathrm{A}$

14. Required Response Date: N/A

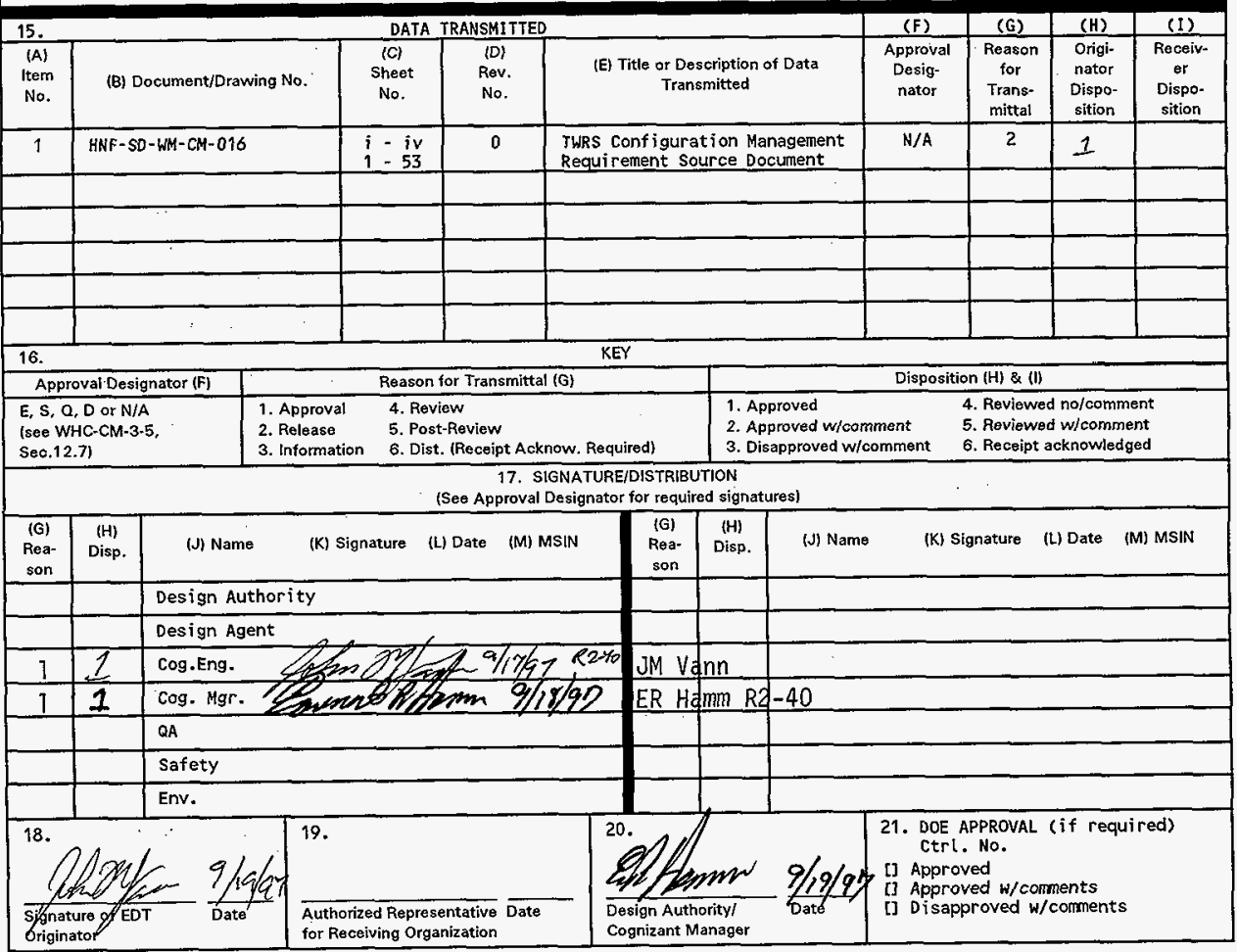




\section{TWRS CONFIGURATION MANAGEMENT REQUIREMENT SOURCE DOCUMENT}

J. M. Vann

Lockheed Martin Hanford Corporation, Richland, WA 99352

U.S. Department of Energy Contract DE-AC06-96RL13200

EDT/ECN: 609868

Org Code: 71300

UC: 2030

B\&R Code: EW3120075

Charge Code: DIN27

Total Pages: $-56,60$

Key Words: Configuration management, change control, TWRS, requirements

Abstract: The TWRS Configuration Management (CM) Requirement Source document prescribes $\mathrm{CM}$ as a basic product life-cycle function by which work and activities are conducted or accomplished. This document serves as the requirements basis for the TWRS CM program. The objective of the TWRS CM program is to establish consistency among requirements, physical/functional configuration, information, and documentation for TWRS and TWRS products, and to maintain this consistency throughout the life-cycle of TWRS and the product, particularly as changes are being made.

TRADEMARK DISCLAIMER. Reference herein to any specific commercial product, process, or service by trade name, trademark, manufacturer, or otherwise, does not necessarily constitute or imply its endorsement, recommendation, or favoring by the United States Government or any agency thereof or its contractors or subcontractors.

Printed in the United States of America. To obtain copies of this document, contact: Document Control Services, P.0. Box 950, Mailstop H6-08, Richland WA 99352, Phone (509) 372-2420;

Fax (509) 376-4989.
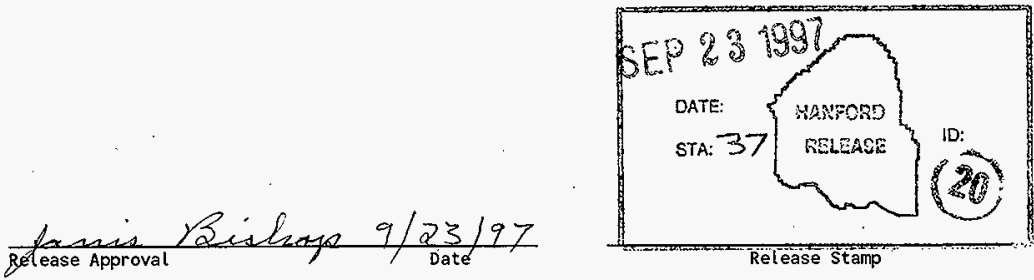
HNF-SD-WM-CM-016, Rev. 0

September 17, 1997

This page intentionally left blank. 
HNF-SD-WM-CM-016

Rev. 0

September 17, 1997

\section{TABLE OF CONTENTS}

1.0 INTRODUCTION

2.0 SCOPE $\quad 2$

$\begin{array}{ll}3.0 & \text { RESPONSIBILITY } \\ \end{array}$

4.0 CONFIGURATION MANAGEMENT PLANNING AND MANAGEMENT

4.1 CM Program Scope $\quad 3$

4.2 CM Plans $\quad$ - 6

$\begin{array}{lll}4.3 & \text { CM Procedures } & 10\end{array}$

4.4 Training 11

4.5 Performance Measurement 11

\begin{tabular}{ll}
5.0 & 12 \\
\hline
\end{tabular}

$\begin{array}{lll}5.1 & \text { Baseline Identification } & 12\end{array}$

5.2 Configuration Item Identification $\quad 14$

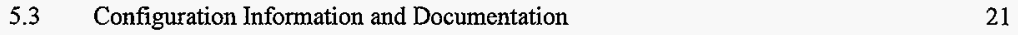

5.4 Data Management and Document Control 24

5.5 Interface Control . $\quad 29$

$\begin{array}{lll}6.0 & \text { CHANGE CONTROL } & 30\end{array}$

6.1 Control Process $\quad 30$

6.2 Change Identification 34

6.3 Change Evaluation and Coordination $\quad 39$

$\begin{array}{lll}6.4 & \text { Change Disposition } & 43\end{array}$

6.5 Change Implementation and Verification 44

7.0 CONFIGURATION STATUS AND ACCOUNTING $\quad$ • 46

7.1 Status of Product/System 46

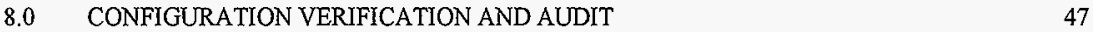

8.1 Design and Document Verification $\quad 47$

8.2 Continuing Performance Audits and Surveillance 50

$\begin{array}{llr}9.0 & \text { GLOSSARY } & 51\end{array}$ 
HNF-SD-WM-CM-016

Rev. 0

September 17, 1997

This page intentionally left blank. 


\section{$1.0 \quad$ INTRODUCTION}

The Tank Waste Remediation Systems (TWRS) Configuration Management (CM) Requirements Source document prescribes $\mathrm{CM}$ as a basic product life-cycle function by which work and activities are conducted or accomplished. This document serves as the requirements basis for the TWRS CM program. This document is intended to be used by those personnel involved in TWRS CM planning and management. This document will be updated when the Fluor Daniel Hanford (FDH) CM Plan is issued. The objective of the TWRS CM program is to establish consistency among requirements, physical/functional configuration, information, and documentation for TWRS and TWRS products, and to maintain this consistency throughout the life-cycle of TWRS and the product, particularly as changes are being made.

This document identifies and consolidates requirements bases that are relevant to the TWRS CM program. The specific DOE Orders, regulations, industry codes/standards, guidance documents, and good industry practices that provide the bases for each TWRS CM requirement are identified immediately following the applicable requirements statement. For application of this document, both of the words "will" and "shall" in requirement statements indicate mandatory compliance.

The TWRS CM program defined in this document is described in accordance with the LMHC Contract Number 80232764-9-K001; DOE standard DOE-STD-1073-93, "Guide for Operational Configuration Management Program; DOE/RL-93-0106, "Tank Waste Remediation System Program Management Policies, Annex 4, Configuration Management Policy;" Electronic Industries Association (EIA)/SS-649, "National Consensus Standard for Configuration Management (August 1995); and Good Practice Guide (GPG)-FM-012, "Configuration and Data Management;" and Lockheed Martin Corporation Corporate Policy Statement, CPS-422, "Configuration Management." 


\subsection{SCOPE}

This document applies to the TWRS CM Program and its implementation across TWRS activities and products throughout the life cycle of TWRS. The TWRS activities and products are identified in the TWRS Work Breakdown Structure (WBS) contained in the TWRS Multi-Year Work Plan (MYWP).

\subsection{RESPONSIBILITY}

The TWRS Configuration Management organization is responsible for implementing configuration management, in accordance with the Lockheed Martin Corporation corporate policy statement CPS-422, "Configuration Management."

1. The TWRS Configuration Management organization establishes configuration management procedures, sufficient to accomplish the requirements of CPS-422.

\section{Requirement Basis:}

A. Lockheed Martin Corporation, CPS-422, Configuration Management, Paragraph 3.2.1. Establish configuration management procedures sufficient to accomplish the requirements of this CPS.

2. The TWRS Configuration Management organization establishes functional responsibility for administration of the company's configuration management program in accordance with the applicable policies and procedures.

\section{Requirement Basis:}

A. Lockheed Martin Corporation, CPS-422, Configuration Management, Paragraph 3.2.2. Establish functional responsibility for administration of the company's configuration management program in accordance with the applicable policies and procedures.

3. The TWRS Configuration Management organization evaluates current and new programs to determine the appropriate level of configuration management requirements.

\section{Requirement Basis:}

A. Lockheed Martin Corporation, CPS-422, Configuration Management Paragraph 3,2.3. Evaluate current and new programs to determine the appropriate level of configuration management requirements. 
HNF-SD-WM-CM-016

Rev. 0

September 17, 1997

4. The TWRS Configuration Management organization monitors and controls program configuration management activities to ensure maximum effectiveness and compliance.

\section{Requirement Basis:}

A. Lockheed Martin Corporation, CPS-422, Configuration Management, Paragraph 3.2.4. Monitor and control program configuration management activities to ensure maximum effectiveness and compliance.

5. The TWRS Configuration Management organization will ensure that adequate provision for configuration management is made in the preparation of proposals.

\section{Requirement Basis:}

A. Lockheed Martin Corporation,CPS-422. Configuration Management Paragraph 3.2.5. Consider and make adequate provision for configuration management in the preparation of proposals.

6. The TWRS Configuration Management organization participates in the preparation of specifications and the review and preparation of prime and subcontract statements of work, including requirements flowdown.

\section{Requirement Basis:}

A. Lockheed Martin Corporation. CPS-422, Configuration Management, Paragraph 3.2.6. Participate in the preparation of specifications and the review and preparation of prime and subcontract statements of work, including requirements flowdown.

\subsection{CONFIGURATION MANAGEMENT PLANNING AND MANAGEMENT}

\subsection{Program Scope}

1. The scope of the TWRS CM program and application of CM principles will be defined in the TWRS CM Program Plan based on importance of the CM principle to the environment, safety, health, and the TWRS mission.

\section{Requirement Bases:}

A. EIA/IS-649. Paragraph 5.1.CM Planning and Management. Plan CM processes for the context and environment in which they are to be performed and manage in accordance with the planning: assign responsibilities; train personnel; measure performance; and assess measurements/trends to effect process improvement.

B. Lockheed Martin Corporation, CPS-422, Configuration Management, Paragraph 2.1. Planning for, documenting and maintaining the company's minimum program configuration management requirements and responsibilities. 
2. Configuration item scope criteria will be defined in the CM Program Plan to select products for control, based on the product's (includes, but is not limited to, facilities and structures, systems, and components [SSCs] importance to the environment, safety, health, and the TWRS mission.

\section{Requirement Bases:}

A. DOE-STD-1073-93, Chapter 1. Section 1.3.1.1, Program Planning. A graded approach should be used to determine the depth of detail necessary and the magnitude of tesources to be invested in each CM program function. Configuration management program planning should include the following:

Issuance by the DOE prime contractor for a site/division-level CM policy directive that announces top management support for the $\mathrm{CM}$ program, defines key roles and responsibilities, provides criteria for the $\mathrm{CM}$ equipment scope, and establishes key terminology and definitions.

B. GPG-FM-012, Paragraph 2.3.5, Configuration Identification. The sites, facilities, structures, systems and components of DOE projects, programs and operating facilities that are important to the environment, safety and health and other structures, systems, and components that are deemed critical to the DOE mission should be included in the configuration management program.

C. DOE-STD-1073-93, Chapter 1. Section 1.3.1.2, Equipment Scope Criteria. The types of equipment to be included in the $\mathrm{CM}$ program should be identified. The equipment scope of the CM program should be based on the functions provided by the SSCS and should include those SSCs involving safety design requirements (those necessary to protect off-site personnel, on-site personnel, and facility workers from nuclear and other hazards), environmental design requirements (those necessary to protect the environment from significant damage or to satisfy environmental requirements or permits), and mission design requirements (those necessary to avoid substantial interruptions of the programmatic mission or severe cost impacts).

3. The grades assigned to items by other management systems will be used to determine the importance of the item and the need to control that item.

\section{Requirement Bases:}

A. DOE-STD-1073-93, Chapter I, Section 1.3.2.2. Systems and Process Boundaries. Establish system and process boundaries to identify components necessary to satisfy design requirements. The boundaries of each system and process should be established in such a manner as to contain the components necessary to satisfy the design requirements for that system or process.

B. DOE-STD-1073-93. Chapter 1. Section 1.3.2.3, Assignment of SSC Grades. Assign SSC grading based upon the design requirements importance. Use SSC Grades to establish appropriate work controls. Each SSC should be assigned a grade based on the most important type of design requirements applicable to it. The SSC grade should be used as the basis for the degree of control on all activities associated with the SSC. 
C. DOE-STD-1073-93, Chapter 1, Section 1 3.2.4, Specific Equipment Scope. On the basis of the equipment scope criteria and the assignment of SSC grades, the specific SSCs included in the CM program should be identified.

D. DOE-STD-1073-93, Chapter 1, Section 1.4.2.5, Facility Grades and SSC Grades. The graded approach involves both the assignment of grades and the subsequent application of those grades in determining the degree of implementation. The importance and priorities of SSCs within a facility need to be considered within the context of the overall importance of the facility. The objective is to ensure that the highest level of attention and resources is applied to the most important SSCs at the most important facilities. Grading should focus on avoiding the cost of applying high levels of attention where such attention is not warranted. It is important that the grading system include consideration of both the overall facility importance grade and the importance grades for the SSCs within the facility.

4. The CM policy ensures traceability of requirements to their source and to their lowest level allocation and the technical baseline. These paths shall be readily identified.

\section{Requirement Basis:}

A. DOE/RL-93-0106, Annex 4, Paragraph 2.12. Technical Baseline Policy. The objective of the policy is to assure traceability of requirements to their source and to their lowest level allocation in the technical baseline. These paths shall be readily identifiable.

5. Documents that represent the approved technical baseline information shall be formally released and controlled. The approved documents (or requirements and design configurations contained in databases) shall provide technical information on which all subsequent engineering and design is based.

\section{Requirement Basis:}

A. DOE/RL-93-0106, Annex 4, Paragraph 2.1.2, Technical Baseline Policy. The Technical Baseline evolves through the stages described in the Systems Engineering Management Policy and Systems Engineering Management Plans (SEMPs). Documents (or databases) that represent the approved technical baseline information shall be formally released and controlled. The approved documents (or requirements and design configurations contained in databases) shall provide technical information on which all subsequent engineering and design is based. Appropriate authority shall authorize release after validation of the element through design review or other approved process. The DOE and M\&O Contractor shall jointly establish the appropriate authority of release, depending on the level and grade of the technical baseline element.

6. The TWRS CM program will be integrated with the engineering, operational, and administrative process defined in WHC-SD-WM-SEMP-002, "TWRS Systems Engineering Management Plan." 
HNF-SD-WM-CM-016

Rev. 0

September 17, 1997

\section{Requirement Basis:}

A. LMHC Contract No. 80232764-9-K001, Paragraph 1.2. Description of Lockheed Martin Hanford Corporation Support to Others. The Subcontractor shall provide support to FDH for Sitewide Systems Engineering. This support is extended, through FDH, to all major subcontractors to: Define, implement, and maintain systems engineering management systems, policies, procedures, and tools. These systems, with their related policies and procedures shall include configuration management, requirements management, and data management.

7. The TWRS CM program shall ensure that open items throughout the life cycle of the product will be dispositioned by a formal resolution process and tracked to completion and closeout, including documentation of their resolution. Safety-significant open items (e.g., discrepancies) will be promptly addressed by existing programs for determining operability and reportability and resolved by those programs.

\section{Requirement Bases:}

A. DOE-STD-1073-93, Chapter 1, Section 1.3.6.4, Sentences 2 and 3, Discrepancy Resolution. The open items should be dispositioned by a formal resolution process and should be tracked to completion and closeout, including documentation of their resolution. Safety-significant open items (i.e., discrepancies) should be promptly addressed by existing programs for determining operability and reportability and resolved by those programs.

B. DOE-STD-1073-93, Chapter 1, Section 1,3.6.5, Regeneration of Missing Critical Design Information. Missing design information should be evaluated to determine which part needs to be regenerated. Missing design information that is critical, including that necessary to support the facility accident analysis and TSRs, should be regenerated in order of priority.

\subsection{Plans}

1. A TWRS CM Program Plan will be developed and maintained that describes the CM program for TWRS, establishes the scope of the program, and defines the requirements and responsibilities for execution of the TWRS CM program. The TWRS CM Program Plan will provide the methodology to establish, upgrade, reconstitute, and maintain consistency among the requirements, product configuration, and product information.

\section{Requirement Bases:}

A. GPG-FM-012, Paragraph 2.3.1, Plans and Procedures. The CM process should be controlled by a CM plan.

B. DOE-STD-1073-93 Chapter 1, Section 1.3.1.1, Program Planning, Item c. Development of the CM program plan, based on the graded approach and initial assessments, that defines the appropriate level of implementation for specific facilities, describes those actions already taken to develop and implement the CM. 
HNF-SD-WM-CM-016

Rev. 0

September 17, 1997

C. DOE/RL-93-0106, Annex 4, Paragraph 1 4, Documents Required From The Managing and Operating $(\mathrm{M} \& \mathrm{O})$ Contractor. The $\mathrm{M} \& \mathrm{O}$ contractor shall submit the following documents to the TWRS Program Office during the life cycle of the program:

- The M\&O Contractor Configuration Management Program Plan shall describe the contractor's configuration management program and describe how the policies contained in this Annex are implemented.

- Technical Baseline documents, including approved changes, that meet the thresholds for DOE approval, as described in Sections 2.1.2 and 2.2.3.

- Configuration Management program assessment results and list of corrective actions, as described in Section 2.3.

- Any other configuration management documents requested by the DOE through the normal contracting process.

D. Lockheed Martin Corporation, CPS-422, Configuration Management Paragraph 3.2.1. Establish configuration management procedures sufficient to accomplish the requirements of this CPS.

E. Lockheed Martin Corporation, CPS-422. Configuration Management, Paragraph 3.2.2. Establish functional responsibility for administration of the company's configuration management program in accordance with the applicable policies and procedures.

2. The TWRS CM Program Plan will define concepts, principles, standard terminology, and standard definitions the CM program.

\section{Requirement Basis:}

A. DOE-STD-1073-93, Chapter 1. Section 1.3.1.3. Concepts and Terminology. Concepts, standard terminology, and standard definitions should be established and maintained for the CM program. They should be based on the concepts, terms, and definitions provided in this Standard.

3. Implementation of CM by TWRS projects and subcontractors will comply with the TWRS CM Program that is described and controlled by the TWRS CM Program Plan.

\section{Requirement Bases:}

A. EIA/IS-649, Paragraph 5.1, Supplier Configuration Management. Performing configuration management includes responsibility for the configuration management performance of subordinate activities (e.g., subcontractors and vendors).

B. GPG-FM-012, Paragraph 2.2. Roles. CM should be an organizationally and procedurally integrated program. 
C. GPG-FM-012, Paragraph 2.3.1, Plans and Procedures. Each non-DOE organization participating in the project should similarly be required to prepare and maintain a $\mathrm{CM}$ plan for their portion of the work that integrates with the project level plan.

4. Line Item Projects will include a CM plan as a component of the project planning documentation.

\section{Requirement Basis:}

A. GPG-FM-012, Paragraph 2.3.1, Plans and Procedures. For Line Item Projects, including Strategic Systems, the project should include a CM plan as a component of the project planning documentation.

5. For Non-line Item Projects, use of a CM plan will be considered based on the graded approach defined in the TWRS CM Program Plan.

\section{Requirement Basis:}

A. GPG-FM-012, Paragraph 2,3.1, Plans and Procedures. For other projects, use of a CM plan should be considered on a graded basis.

6. Each CM plan will describe how CM is accomplished; assign responsibilities; and describe how consistency among the source requirements, the product's configuration, configuration information, and the $\mathrm{CM}$ records is archived and maintained throughout the applicable phases of the product's life cycle.

\section{Requirement Bases:}

A. EIA/IS-649. Paragraph 5.1. Supplier Configuration Management. Performing configuration management includes responsibility for the configuration management performance of subordinate activities (e.g., subcontractors and vendors).

B. GPG-FM-012, Paragraph 2.3.1, Plans and Procedures. Each non-DOE organization participating in the project should similarly be required to prepare and maintain a $\mathrm{CM}$ plan for their portion of the work that integrates with the project level plan.

7. Each $\mathrm{CM}$ plan will describe how $\mathrm{CM}$ is accomplished; assign responsibilities; and describe how consistency among the product definition, the product's configuration, configuration information, and the CM records is archived and maintained throughout the applicable phases of the product's life cycle.

\section{Requirement Bases:}

A. EIA/IS-649, Paragraph 5.1.2. CM Plan. A CM plan describes how CM is accomplished and how consistency between the product definition, the product's configuration, and the $\mathrm{CM}$ records is achieved and maintained throughout the applicable phases of the product's life cycle. 
B. GPG-FM-012, Paragraph 2.3.1, Plans and Procedures. The plan should include discussion of how $\mathrm{CM}$ will be conducted on the project and what items will be so managed.

8. Each CM plan will address initiation of immediate corrective actions for substantive weaknesses discovered during the initial assessments.

\section{Requirement Basis:}

A. DOE-STD-1073-93, Chapter 1, Section 1.3.1.1, Program Planning, Item b. Initiation of immediate corrective actions for substantive weaknesses discovered during the initial assessments.

9. Actions necessary to establish and implement the TWRS CM program will be identified in the TWRS CM Implementation Plan.

\section{Requirement Basis:}

A. DOE-STD-1073-93, Chapter 1, Section 1.3.1.6, Procedures. After DOE review of the CM program plan, action plans and specific $\mathrm{CM}$ implementation procedures consistent with the action plans should be developed. In addition, governing procedures that correlate the implementation procedures with the CM program plan should be developed and maintained.

The $\mathrm{CM}$ program should include training on $\mathrm{CM}$ concepts, terminology, definitions, and procedures.

10. An assessment of $\mathrm{CM}$ implementation will be performed to determine the need for a Design Reconstitution program. This assessment includes the graded approach defined in the TWRS CM program plan that will be used to determine the need for a Design Reconstitution program.

\section{Requirement Basis:}

A. DOE-STD-1073-93 Chapter 1, Section 1.3.6.1, Program Plans and Procedures. The DR program plan should be based on the initial assessments and the graded approach.

11. Where design reconstitution is necessary, a program plan, an action plan, and implementing procedure(s) will be developed.

\section{Requirement Bases:}

A. DOE-STD-1073-93, Chapter 1, Section 1.3.6.1, Program Plans and Procedures. A program plan, an action plan, and implementing procedures should be developed for the Design Reconstitution (DR) adjunct program.

B. DOE-RL-93-0106, Annex 4, Paragraph 2,4,13, Design Reconstitution. A Design Reconstitution program shall establish, organize, and document design information on selected critical SSCs where such information is missing or inadequate. The critical SSCs shall be graded accordingly. Design reconstitution is a one-time effort to identify, 
tetrieve, and extract, evaluate, verify, validate, and regenerate missing critical requirements and design basis. The adequacy of existing design information shall be technically evaluated to determine the extent and priority of the reconstitution needed.

12. The Design Reconstitution program(s) shall be implemented in stages to provide a timely initial set of design information and the incorporation of additional data as it becomes available.

\section{Requirement Basis:}

A. DOE-STD-1073-93, Chapter 1, Section 1.3.6.1, Program Plans and Procedures. The DR adjunct program should be implemented in stages to provide a timely initial set of design information and more information as it becomes available.

13. The Design Reconstitation Program Plan shall prioritize the need to establish a sound basis for performing work and providing for the performance of related tasks. As-building will be applied to design reconstitution where the facility and design documents would reflect the actual existing facility configuration.

\section{Requirement Basịs:}

A. DOE-STD-1073-93, Chapter 1, Section 1.3.6.1, Program Plans and Procedures. It should include prioritization of the development and issuance of Design Information Summary (DISs). DISs for systems and technical topics necessary to support the facility accident analysis and Technical Safety Requirement (TSRs) should receive the highest priority.

14. The Design Reconstitution program plan shall address the same topics identified for the CM Program Plan.

\section{Requirement Basis:}

A. DOE-STD-1073-93, Chapter 1. Section 1.3.6.1, Program Plans and Procedures. The DR program plan should address the same topics identified for the $\mathrm{CM}$ program plan.

\subsection{Procedures}

1. Procedures will be used to communicate how $\mathrm{CM}$ principles are to be implemented. These procedures will communicate and implement the requirements of this S/RID.

\section{Requirement Bases:}

A. EIA/IS-649, Paragraph 5.13. Implementation Procedures. Prepare procedures to define how each $\mathrm{CM}$ process will be accomplished.

B. GPG-FM-012, Paragraph 2.3.1. Plans and Procedures. Procedures should be established by Program Offices, DOE Field Elements, and DOE contractors for the control of changes to configuration items, baselines and supporting documents. 
2. Implementation of $\mathrm{CM}$ will address existing processes and procedures. Wherever practical, $\mathrm{CM}$ activities will be included as steps in procedures for related activities, rather than in standalone $\mathrm{CM}$ procedures, so the steps are integral to the process(es) that will be utilized for $\mathrm{CM}$ implementation.

\section{Requirement Basis:}

GPG-FM-012, Paragraph 2.3.1, Plans and Procedures. CM-related procedures should incorporate existing procedures, programs, and processes. Wherever practical, $\mathrm{CM}$ activities should be included as steps in procedures for related activities, rather than in standalone CM procedures, so the steps are integral to the process(es).

\subsection{Training}

TWRS shall develop and implement a training program that includes configuration management concepts, terminology, definitions, implementing procedures, and roles and responsibilities.

\section{Requirement Bases:}

A. EIA/IS-649, Paragraph 5.1.4, Training. Conduct training so that all responsible individuals understand their roles and responsibilities and the procedures for implementing configuration management processes.

B. GPG-FM-012, Paragraph 2.4.2.6. Training. Program Office and Field Elements should develop and implement a training program that (1) provides for understanding and proper implementation of the configuration management program guidelines and procedures and (2) ensures that appropriate facility operation and maintenance personnel are familiar with modified systems and equipment.

\subsection{Performance Measurement}

1. Performance measurements shall be established to monitor the effectiveness of the configuration management program. Resultant performance indicators will be used to evaluate and improve the configuration management program, plans, and procedures, and implementation.

\section{Requirement Bases:}

A. ELA/IS-649. Paragraph 5.1.5, Performance Measurement. Assess the effectiveness of CM plan implementation and performance of the configuration management discipline with defined metrics (performance indicators).

B. GPG-FM-012, Paragraph 3.0, Measuring for Results. The effectiveness of configuration and data management planning and implementation should be assessed using established performance measures.

C. Lockheed Martin Corporation, CPS-422, Configuration Management, Paragraph 2.8. Monitoring and ensuring the integrity of systems essential to the accomplishment of an effective configuration management program. 
HNF-SD-WM-CM-016

Rev. 0

September 17, 1997

\subsection{CONFIGURATION IDENTIFICATION}

\subsection{Baseline Identification}

1. Baseline requirements and data will be controlled through all phases of the projects and operating facilities. Baseline documents will establish traceability of requirements through all levels of documentation and to the configuration items. Regulatory and other source requirements depicted in documents that describe configuration items shall be readily traceable to their origin through configuration documents and information.

\section{Requirement Bases:}

A. GPG-FM-012, Paragraph 2.3.6, Traceability. Configuration management should require traceability of technical baseline requirements and data through all phases of DOE programs, projects and operating facilities. Technical baseline documents should establish traceability of requirements through all levels of documentation, and to the configuration items. Regulatory and other design basis requirements depicted in documents which describe configuration items should be readily traceable to their origin through design. requirements documents, etc.

B. DOE-STD-1073-93, Chapter 1, Section 1.3.6.6, Preparation and Issuance of Design Information Summaries. Extracted design requirements should be entered into the $\mathrm{CM}$ equipment database promptly after verification and technical validation. Design information summaries should include a system description (including systems interface information), system operability requirements, system-level design requirements, component-level design requirements, the design basis, and related design topical information. They also should identify design requirements by type; attributes of the design that were not mandatory for the designer should be distinguished from other types of design requirements. The authorization basis should be clearly distinguished from other aspects of the design basis. The DISs should be written for easy use by individuals at all levels of experience.

C. DOE/RL-93-0106, Annex 4, Paragraph 2.1.2. Technical Baseline Policy. Baseline requirements shall be traceable to their source. External, imposed requirements shall be traceable to their source document, e.g., Codes of Federal Regulations, DOE orders. Derived requirements shall be traceable to the design basis documents that establish the requirements. This policy does not impose a specific methodology or tool for linking the requirements for traceability purposes, by does require that such links be established.

D. DOE/RL-93-0106, Annex 4, Paragraph 2.1.2. Technical Baseline Policy. The M\&O Contractor and Engineering Contractors shall maintain traceability between the Technical Baseline requirements and the Design Basis documentation. The Design Basis traceability path and the Design Basis documents shall be readily retrievable for each requirement. 
HNF-SD-WM-CM-016

Rev. 0

September 17, 1997

E. Lockheed Martin Corporation, CPS-422, Configuration Management, Paragraph 2.2. Establishing and maintaining program baseline definitions (hardware/software) through approved requirements/specifications, applicable documents, statements of work and technical data packages.

F. Lockheed Martin Corporation. CPS-422, Configuration Management, Paragraph 2.4. Disseminating baseline information to program regarding the applicability of customer specifications, standards, and program-unique (configuration item) specifications.

G. Lockheed Martin Corporation, CPS-422, Configuration Management, Paragraph 2.5. Managing program baselines and ensuring proper authorization of changes thereto.

2. The TWRS baselining process will allocate technical requirements to subsequent levels of detail throughout the design, construction, operations phases, and decommissioning of materials and components that shall be traceable to their application and physical location.

\section{Requirement Basis:}

A. GPG-FM-012, Paragraph 2.3.6, Traceability. The baselining process allocates technical requirements to subsequent levels of detail. Throughout the design, construction and operations phases, materials and components should be traceable to their application and physical location.

3. TWRS shall establish and maintain a single integrated baseline that will identify and combine the technical, schedule, and cost information relevant to TWRS products (including facilities and SSCs) and activities.

\section{Requirement Bases:}

A. EIA/IS-649, Paragraph 5.2.5, Baselines. A baseline identifies an agreed-to-description of the attributes of a product at a point in time and provides a known configuration to which changes are addressed.

B. GPG-FM-012, Paragraph 2.3.2, Technical Baseline Identification. The technical baseline defines the physical and functional configuration of the project's end product(s). Baseline management controls the scope, cost and schedule baselines and integrates with configuration management which controls the technical baseline. Data management controls information on the project and the configuration of the end products $(s)$. The technical baseline consists of a top-down set of requirements in which all subsidiary requirements flow down from the requirements above them.

4. Configuration items will be uniquely identified in the technical baseline documentation.

\section{Requirement Basis:}

A. GPG-EM-012, Paragraph 2.3.5, Configuration Identification. The configuration items should be identified in the technical baseline documentation and should have a unique identifier (e.g., component or equipment number). The unique identifier is needed to 
HNF-SD-WM-CM-016

Rev. 0

September 17, 1997

ensure consistency, retrievability, and traceability of technical and baseline documentation for configuration items.

B. DOE/RL-93-0106, Annex 4, Paragraph 2.1.1, Structures, Systems, and Components Subject to Configuration Management. Each SSC shall be uniquely identified. Grades of importance shall be assigned to each SSC to determine priorities and proper levels of attention and resource allocation.

5. As the TWRS project becomes more defined, subordinate projects shall be identified. Each subordinate project shall have a set of technical baseline documents. Each subordinate project shall have a top-level technical baseline document (e.g., a Design Requirements Document), that defines the top level requirements for that project. Those requirements shall be directly traceable to the TWRS project technical baseline requirements.

\section{Requirement Basis:}

A. DOE/RL-93-0106, Annex 4, Paragraph 2.1.2. Technical Baseline Policy. As the program becomes more defined, projects shall be identified. Each project shall have a set of technical baseline documents. Each project shall have a top-level technical baseline document (e.g., a Design Requirements Document), that defines the top level requirements for that project. Those requirements shall be directly traceable to the program technical baseline requirements.

6. The TWRS tank waste inventory shall be controlled in the manner similar to the technical baseline. The inventory configuration shall provide the consistent and approved information needed for the technical planning and engineering required to remediate the tank waste. This inventory configuration used for technology selection and engineering design shall be referenced in the design basis documentation.

\section{Requirement Basis:}

A. DOE/RL-93-0106, Annex 4, Paragraph 2.1.4. Waste Inventory Configuration Policy. The TWRS tank waste inventory shall be controlled in the manner similar to the technical baseline. The inventory configuration shall provide the consistent and approved information needed for the technical planning and engineering required to remediate the tank waste. This inventory configuration used for technology selection and engineering design shall be referenced in the design basis documentation.

\subsection{Configuration Item Identification}

1. Products will be selected and identified as configuration items based on the graded approach defined in the TWRS CM program plan. Facility-specific configuration items will be identified based on the configuration item scope criteria and the assignment of SSC grades. 


\section{Requirement Bases:}

A. GPG-FM-012, Paragraph 2.3.5. Configuration Identification. The sites, facilities, structures, systems and components of DOE projects, programs and operating facilities that are important to the environment, safety and health and other structures, systems and components that are deemed critical to the DOE mission should be included in the configuration management program.

B. DOE-STD-1073-93 Chapter 1, Section 1.3.2.4, Specific Equipment Scope. On the basis of the equipment scope criteria and the assignment of SSC grades, the specific SSCs included in the CM program should be identified.

2. The TWRS SSC grading structure shall be developed. The grades shall be used to identify the organizational approval levels for SSC documentation.

\section{Requirement Basis:}

A. DOE/RL-93-0106, Annex 4. Paragraph 2.11. Structures, Systems, and Components Subject to Configuration Management. The grading structure shall be developed by the M\&O contractor, and approved by the TWRS Program Office. The grades shall be used to identify the organizational approval levels for SSC documentation.

3. Computer software and associated documentation, including digital data, will be identified and controlled based on the graded approach defined in the TWRS CM program plan. Such software will be controlled as a configuration item. Software designated to be controlled shall be uniquely identified and regarded as part of the technical baseline. Software that should be included in the CM program includes:

- Operations and process control;

- Protection systems;

- Engineering development, design analyses, evaluation, and assessment;

- Mathematical models;

- Database or document indexes when used as the controlled source of information for the above;

- Computer aided design/manufacturing/engineering (CAD/CAM/CAE).

\section{Requirement Bases:}

A. ElA/IS-649, Paragraph 5.6.1, Digital Data Identification. Apply digital data identification rules to maintain document, document representation, and file version relationships.

B. GPG-FM-012, Paragraph 2.3.7, Software CM. The CM program should require that critical computer software and associated documentation be identified and controlled. 
HNF-SD-WM-CM-016

Rev. 0

September 17, 1997

Software designated to be controlled should be uniquely identified and established as part of the technical baseline. Software that should be included in the CM program includes:

- operations and process control;

- $\quad$ protection systems;

- engineering development, design analyses, evaluation, and assessment;

- mathematical models;

- database or document indexes when used as the controlled source of information for the above; and

- computer aided design/ manufacturing/engineering (CAD/CAM/CAE).

4. The TWRS products, individual units of a product, or series of like units of a product will be assigned unique identifiers so that they can be distinguished from other products; one . configuration of a product can be distinguished from another; the source of a product can be determined; and the correct product information can be retrieved.

\section{Requirement Bases:}

A. EIA/IS-649. Paragraph 5.2.3. Product Identifiers. All products are assigned unique identifiers so that one product can be distinguished from other products; one configuration of a product can be distinguished from another; the source of a product can be determined; and the correct product information can be retrieved.

B. EIA/IS-649 Paragraph 5.2.3.1, Identifying Individual Units of a Product. Individual units of a product are assigned a unique product unit identifier when there is a need to distinguish one unit of the product from another unit of the product.

When a product is modified, it retains its original product unit identifier even though its part identifying number is altered to reflect a new configuration.

C. EIA/IS-649 Paragraph 5.2.3.2. Identifving Individual Units of a Product. A series of like units of a product is assigned a unique product group identifier when it is unnecessary or impracticable to identify individual units but nonetheless necessary to correlate units to a process, date, event, or test.

D. EIA/IS-649. Paragraph 5,6.1, Digital Data Identification. Apply digital data identification rules to maintain document, document representation, and file version relationships.

E. GPG-FM-012, Paragraph 2.3.5, Configuration Identification. The configuration items should be identified in the technical baseline documentation and should have a unique identifier (e.g., component or equipment number). The unique identifier is needed to ensure consistency, retrievability, and traceability of technical and baseline documentation for configuration items. 
The level of identification required varies depending on the importance of the configuration item and the indentured level from which documentation needs to be retrieved. Structures, systems and components important to safety require a more detailed identification than other SACS to ensure traceability of requirements throughout the life of the project, program or operating facility.

5. The boundaries of each system and process shall be established to contain the components necessary to satisfy the design requirements for that system or process.

\section{Requirement Bases:}

A. EIA/IS-649, Paragraph 5.1.1, Identifying Context and Environment. To determine the specific $C M$ value adding functions and levels of emphasis for a particular product, identify the context and environment in which $\mathrm{CM}$ is to be implemented.

B. GPG-FM-012, Paragraph 2.3.3, Establishment of Baselines. Development of baselines for DOE programs, projects, and operating facilities should adhere to the following management concepts set forth by DOE 0 430.1:

- identification, documentation, and approval of basic requirements;

- specification of a systematic process for development;

- formal identification and approval of baselines;

- $\quad$ specification of allowed variances from the approved baselines;

- regular reporting and assessment of status against the approved baselines; and

- corrective management action (that may include baseline revision) in the event a variance exceeds a prescribed threshold.

6. An equipment list will be used to specify which SSCs are included as configuration items. This equipment list will be in the form of a Master Equipment List (MEL). The Safety Equipment List (SEL) when developed and maintained as needed will be a subset of the MEL.

\section{Requirement Bases:}

A. GPG-FM-012, Paragraph 2.3.9, Data Management. New facilities should develop a Master Equipment List (MEL) database during design and construction. This list should contain structures, systems and components (SSCs) selected by the Field Element and the contractor based upon safety grades assigned to the SSCs.

Each existing facility classified as a Hazards Category Class 3 or higher should develop a Safety Equipment List (SEL) for Safety Class 1 equipment only. The SEL should contain the data specified above and should be a subset of the MEL.

B. DOE/RL-93-0106, Annex 4, Paragraph 2.1.6, Master and Safety Equipment List Policy. New facilities designed and constructed for TWRS Program shall develop a Master 
Equipment List (MEL) database. This list shall contain SSCs selected by the TWRS Program Office and the M\&O contractor based upon the grades assigned to the SSCs.

7. The TWRS MEL shall have the following features, as a minimum:

- All SSCs will be classified (where applicable) by categories of interest to the users of the MEL.

- SSC lists shall be extractable by category.

\section{Requirement Bases:}

A. GPG-FM-012, Paragraph 2.3.9, Data Management. The list should have the following features, as a minimum: All SSCs should be classified (where applicable) by engineering system, start-up system, operating system, safety class, hazard category, instrument loop number, piping line number, circuit number, plant location, applicable Work Breakdown Structure (WBS) element, and any other category of interest to the users of the MEL. SSC lists should be extractable by category, for example, a list of all Safety Class 1 items.. Each SSC should reference its unique identification number, engineering drawing or specification number, and other related documents, for example, applicable Safety Analysis Reports (SARs), Interface Control Document, spare parts list, and test procedures.

B. DOE/RL-93-0106, Annex 4, Paragraph 2.1.6, Master and Safety Equipment List Policy. The MEL shall have the following features, as a minimum:

- All SSCs shall be classified (where applicable) by engineering system, start-up system, operating system, safety class, hazard category, instrument loop number, piping line number, circuit number, plant location, applicable Work Breakdown Structure element, and any other category of interest to the users of the MEL.

- SSC lists shall be extractable by category, for example, a list of all Safety Class 1 items.

- Each SSC shall reference its unique identification number, engineering drawing or specification number, and other related documents, for example, applicable Safety Analysis Reports, Interface Control Document, spare parts list, and test procedure.

- Operation and Maintenance Procedures shall be cross-referenced to their associated SSCs and operating systems as applicable.

- Each existing TWRS Program facility classified as Hazards Category Class 3 or higher shall develop a Safety Equipment List (SEL) for Safety Class 1 equipment only. The SEL shall contain the data required above and shall be a subset of the MEL. 
HNF-SD-WM-CM-016

Rev. 0

September 17, 1997

8. Design requirements shall be incorporated into the MEL so that it correlates each SSC with the SSC grade, the design requirements, technical topics involved, and associated documentation.

\section{Requirement Basis:}

A. DOE-STD-1073-93, Chapter 1, Section 1.3.2.1, Establishment of Design Requirements, Item. The design requirements should be incorporated into an equipment database that correlates each SSC with the SSC grade, the design requirements, technical topics involved, and associated documentation.

9. For each SSC the MEL will reference its unique identification number, engineering drawing or specification number, and other related documents; for example, applicable Safety Analysis Reports (SARs), Interface Control Documents, spare parts lists, and test procedures. Operating and maintenance procedures shall be cross-referenced to their associated SSCs and operating systems as applicable.

\section{Requirement Bases:}

A. GPG-FM-012, Paragraph 2.3.9. Data Management. Each SSC should reference its unique identification number, engineering drawing or specification number, and other related documents, for example, applicable Safety Analysis Reports (SARs), Interface Control Document, spare parts list, and test procedure.

Operating and maintenance procedures should be cross-referenced to their associated SSCs and operating systems as applicable.

B. GPG-FM-012, Paragraph 2.3.2, Technical Baseline Identification. Data management controls information on the project and the configuration of its end product(s).

C. DOE-STD-1073-93, Chapter 1, Section I 3.2.1 Paragraph c. The design requirements should be incorporated into an equipment database that correlates each SSC with the SSC grade, the design requirements, technical topics involved, and associated documentation.

10. An as-built configuration program will be established to ensure the as-built configuration for existing facilities are identified and controlled. Technical variances shall be documented when the as-built configuration vary from the technical baseline. The document describing the variance, with its disposition, shall be related to its associated item in the MEL database. The disposition shall include the allowable duration of the nonconformance and required corrective actions to eliminate further nonconformances. If the as-built configuration does not meet the regenerated requirements, then the variance must be resolved through formal change control or through the nonconformance process.

\section{Requirement Bases:}

A. DOE/RL-93-0106, Annex 4, Paragraph 2.1.5, As-Built Configuration Policy. The as-built configuration for existing facilities shall be identified and controlled as described in Section 2.4.1. 
B. DOE/RL-93-0106. Annex 4, Paragraph 2.1.7. Configuration Nonconformance Policy. From time-to-time the as-built configuration may vary from the technical baseline. Technical variances shall be documented. The document describing the variance, with its disposition shall be related to its associated item in the MEL database. The disposition shall include the allowable duration of the nonconformance and required corrective actions to eliminate further nonconformance. The approval level of the nonconformance disposition shall be at the same release level affected by the nonconformance. (See Section 2.1.2)

For existing facilities, if the technical baseline and the design basis are unknown they must be regenerated in accordance with the Design Regeneration Program described in Section 2.4.1. If the as-built configuration does not meet the regenerated requirements, then the variance must be resolved through formal change control or through the nonconformance process.

\subsection{Configuration Information and Documentation}

1. A determination will be made as to which type of configuration item information is necessary due to its importance to the environment, safety, health, and the TWRS mission. Information controlled should include baseline documentation, specifications, procedures, operating records and documentation, drawings, vendor technical manuals, and certain correspondence. This information will be controlled as configuration information.

\section{Requirement Bases:}

A. DOE-STD-1073-93, Chapter 1, Section 1.3.3.1, Identification of Documents. The types of documents that need to be included in the CM program should be determined, and document owners should be established for each of these document types. The document owners should be responsible for the technical content of assigned documents.

B. DOE-STD-1073-93, Chapter 1, Section 1,3.3,1, Identification of Documents. Within each document type, the specific documents to be included in CM document control should be identified for each SSC. The document owners should establish priorities for document revision and retrieval.

C. GPG-FM-012, Paragraph 2.8, Document Control for CM. A document control system should be established to ensure that only accurate and approved technical information is available for the performance of program and project activities and facility operations, information controlled should include baseline documentation, specifications, procedures, operating records and documentation, drawings, vendor technical manuals, and certain correspondence.

2. Owners shall be established for each set of configuration information. The owners shall be responsible for the technical content of assigned information and for establishing priorities for information revision and retrieval. 


\section{Requirement Bases:}

A. DOE-STD-1073-93, Chapter 1, Section 1.3.3.1, Identification of Documents. The types of documents that need to be included in the $\mathrm{CM}$ program should be determined, and document owners should be established for each of these document types. The document owners should be responsible for the technical content of assigned documents.

B. DOE-STD-1073-93, Chapter I, Section 1.3.3.1, Identification of Documents. Within each document type, the specific documents to be included in CM document control should be identified for each SSC. The document owners should establish priorities for document revision and retrieval.

3. The source document/requirement(s) for configuration information will be identified and formally reviewed throughout the life cycle of a defined configuration item.

\section{Requirement Basis:}

A. DOE-STD-1073-93, Chapter 1, Section 1.3.6.2. Identification and Retrieval of Source Information. The objective and scope of source documents to be reviewed should be defined for each document identification and retrieval stage. The recommended stages are the formal review, the smart search, and the comprehensive search. The formal review should address those on-hand documents, such as the facility safety analysis and TSRs, that contain summary-type design information; the smart search should identify and retrieve those types of documents that can be identified as most likely to contain design requirements; and the comprehensive search should identify and retrieve any remaining documents that might contain design information, including DOE correspondence and vendor correspondence.

4. Information that defines a configuration item (describes the functional, performance, and physical attributes of the configuration item) will be controlled as configuration information.

\section{Requirement Basis:}

A. EIA/IS-649, Paragraph 5.2.1, Product Information. Configuration documentation defines the functional, performance, and physical attributes of a product. Other product information is derived from configuration documentation:

5. Traceability of technical requirements will be provided by uniquely identifying the configuration items to the associated documentation. Data management systems will be used to cross-reference the appropriate documents to configuration items.

\section{Requirement Basis:}

A. GPG-FM-012, Paragraph 2.3.6, Traceability. Traceability of technical requirements should be established by uniquely identifying configuration items and the associated documentation. Data management systems should be utilized to cross reference the appropriate documents to configuration items. 
6. Design requirements will be formally established and maintained. Design requirements for new configuration items and modifications to existing items will be established, categorized, and documented as they are developed, in a form amenable to review and input to the equipment database.

\section{Requirement Basis:}

A. DOE-STD-1073-93, Chapter 1, Section 1.3.2.1, Establishment of Design Requirements. The design requirements should be formally established and maintained.

(a) For each SSC, the design requirements should be categorized into the types established by the equipment scope criteria.

(d) The design requirements for new facilities and modification to existing facilities should be established, categorized, and documented as they are developed, in a form amenable to review and addition to the equipment database.

7. A technical management review will be performed to determine the adequacy of the design requirements and design basis. If the design requirements or design basis are not fully documented, not accurate, or not complete, the design requirements should be reconstituted to the extent identified by the design reconstitution program.

\section{Requirement Bases:}

A. DOE-STD-1073-93. Chapter 1. Section 1.32.1. Establishment of Design Requirements, Item (b). A technical management review should be performed to determine the adequacy of the design requirements. If the design requirements are not fully documented, not accurate, or not complete, the design requirements should be reconstituted to the extent identified by the design reconstitution adjunct program.

B. DOE-STD-1073-93, Chapter 1, Section 1.3.2.5, Establishment of Design Basis. Establish, correlate with the design requirements, document and maintain the design basis. Perform technical management review to determine adequacy of existing SSC design basis.

Establish and document the design basis for new or modified design requirements as the design evolves. The design basis for new or modified design requirements should be established and documented as these requirements are developed.

8. The design basis will be established, correlated with the design requirements, documented, and maintained as the design evolves. The design basis for new or modified design requirements will be established and documented as these requirements are developed. 
HNF-SD-WM-CM-016

Rev. 0

September 17, 1997

\section{Requirement Basis:}

A. DOE-STD-1073-93. Chapter 1. Section 1.3.2.5. Establishment of Design Basis. Establish, correlate with the design requirements, document and maintain the design basis. Perform technical management review to determine adequacy of existing SSC design basis.

Establish and document the design basis for new or modified design requirements as the design evolves. The design basis for new or modified design requirements should be established and documented as these requirements are developed.

9. Technical review and identification of design information from each source document should include both design requirements and design basis information. Extracted design information will be identified according to the applicable SSC, type of SSC, technical topic, and whether it is a design requirement or design basis. The technical review and identification of design information from each source document should be complete, so the document does not have to be reconsidered during subsequent searches and review.

\section{Requirement Basis:}

A. DOE-STD-1073-93, Chapter I, Section 1 3.6.2. Paragraph b. Identification and Retrieval of Design Information. Technical review and identification of design information from each source document should include both design requirements and design basis information. Extracted design information should be identified as to the applicable facility SSC, type of SSC, technical topic area, and whether it is a design requirement or design basis. The technical review and identification of design information from each source document should be complete, such that the document does not have to be reconsidered during subsequent searches and review.

\subsection{Data Management and Document Control}

1. Computerized information applications will be subject to the requirements and guidelines of the configuration management program.

\section{Requirement Bases:}

A. EIA/IS-649, Paragraph 5.6, Configuration Management of Digital Data. Apply configuration management principles to ensure the integrity of digital representations of product information and other data.

B. DOE-STD-1073-93, Chapter 1, Section 1.3.1.5, Databases. Databases for use in the identification, storage, control, and retrieval of information important to CM should be established, and policy and criteria for their use should be defined.

C. DOE-RL-93-0106, Annex 4, Paragraph 2.5, Computer Software Configuration Management Policy. Computer software is part of the SSCs and shall be graded and subject to the same type of configuration controls as other SSCs. Computer software configuration management applies to all TWRS custom and commercial software and associated documentation used for scientific analysis, engineering design and analysis, and physical system operational applications. 
Software Configuration Management shall be embedded in the process of acquiring, developing, and maintaining software to support the analysis, design, and operation of TWRS Program SSCs using appropriate software engineering and quality assurance procedures. These procedures shall assure that software documentation is provided for each stage of the software development and operational life cycles. They shall describe the methods to be used for the qualification, verification, and validation requirements and software configuration management controls.

2. A computerized information system shall collect, store, and maintain configuration management technical baseline information and changes thereto.

\section{Requirement Basis:}

A. GPG-FM-012, Paragraph 2,3.9, Data Management. Computerized information applications should be used to collect, store, and maintain configuration management technical baseline information and changes thereto. When used, the design, development, implementation, and use of these applications should be subject to the guidelines of the configuration management program.

3. A technically correct and readily accessible document control system will be used for the control, tracking, storing and retrieving configuration information (drawings, forms, documents/images, procedures, etc.) documents. The document control system shall be proceduralized to ensure the appropriate control of configuration products. Only the currently-approved revisions of configuration information (includes digital data) shall be used.

\section{Requirement Bases:}

A. EIA/IS-649, Paragraph 5.6.4, Data Version Control and Management of Review Comment. Annotation, and Disposition. Apply disciplined version control to manage document review electronically.

B. GPG-FM-012, Paragraph 2.8, Document Control for CM. Programs, projects and operating facilities should establish a document control program that ensures technically correct and readily accessible information is provided to program and project participants and to support facility operations.

Technically accurate and approved information written in a clear and concise format is needed to support safe and reliable program and project activities and facility operations.

C. GPG-FM-012. Paragraph 2.8.1, Document Control Administration. A document control system should be established to ensure that only accurate and approved technical information is available for the performance of program and project activities and facility operations, information controlled should include baseline documentation, specifications, procedures, operating records and documentation, drawings, vendor technical manuals, and certain correspondence. 
HNF-SD-WM-CM-016

Rev. 0

September 17, 1997

4. Configuration information shall be uniquely identified and information management systems proceduralized so that:

- Configuration information (controlled documents and information) is reviewed, approved, changed, and released through formal control processes

- Changes to configuration information are reviewed, approved, changed, and released through formal change control processes

- Owners for configuration information are identified

A cycle is established for the recall and review of the configuration information to ensure its continued validity

- Controlied documents and information are kept current by controlled distribution, including a receipt acknowledgment process

- Users needing controlled copies have ready access to current revisions of controlled copies

- Databases providing revision level information are controlled and maintained current

- Status of digital documents is identified and maintained

- Record retrieval systems are in place that allow timely retrieval of historical documents/information and the cross-referenced material

Records of configuration information will be stored and protected

Retention time for configuration information will be established

Effective dates are established for configuration information that allow for changes to configuration information and related training.

\section{Requirement Bases:}

A. EIA/S-649, Paragraph 5.6.2, Data Status_Level Management. Apply business rules using data status levels for access, change management, and archiving of digital data documents.

B. EIA/IS-649, Paragraph 5,6.3, Maintenance of Data and Product Configuration Relationships. Maintain relationships between digital data, data requirements, and the related product configuration to ensure accurate data access.

C. EIA/IS-649, Paragraph 5.6.4, Data Version Control and Management of Review, Comment, Annotation, and Disposition. Apply disciplined version control to manage document review electronically. 
HNF-SD-WM-CM-016

Rev. 0

September 17, 1997

D. EIA/IS-649, Paragraph 5,6,5, Digital Data Transmittal. Ensure that transmitted digital data product is useable.

E. GPG-FM-012, Paragraph 2.8, Document Control for CM. Controlled documents are uniquely identified and identification systems are proceduralized. Controlled documents are reviewed, approved, changed, and released through change control processes. Controlled documents are kept current by controlled distribution, including a receipt acknowledgment process. Users needing controlled copies have ready access to current revisions of controlled copies. Data bases providing revision level information are controlled and maintained current. Records of configuration information will be stored and protected. Retention time for configuration information will be established. Record retrieval systems are in place that allow timely retrieval of historical documents and the cross-referenced material in those documents. Effective dates are established for configuration information that allow for changes to configuration information and related training.

F. DOE-STD-1073-93, Chapter 1 Section 1.3.3. Document Control Element. The objective of the document control element is to identity and maintain documents within the $\mathrm{CM}$ program consistent with the physical configuration and design requirements.

G. DOE-STD-1073-93, Chapter 1, Section 1 3.3.2. Storage. Store and protect records of CM documents. Establish $\mathrm{CM}$ document retention time.

H. DOE-STD-1073-93, Chapter 1, Section 1.3.3.3, Control and Tracking. Ensure only current revision of $\mathrm{CM}$ document is in use. Incorporate $\mathrm{CM}$ document revisions in a timely manner supported by priority, complexity, and overlap. Establish CM document database to reflect current status, pending changes, and other necessary control for control and status.

I. DOE-STD-1073-93, Chapter 1, Section 1,3,3,4, Retrieval. Establish CM document retrieval time based upon a graded priority determined by the document owner. Identify documents within the $\mathrm{CM}$ document database. Identify pending changes with issuance of CM documents.

4. Drawings will be controlled to ensure they reflect the current configuration of structures, systems, and equipment. Similarly, vendor manuals (or equivalent) used for facility operation will be controlled to ensure they are applicable to installed equipment and contain complete and current technical information.

\section{Requirement Basis:}

A. GPG-FM-012, Paragraph 2.8. Document Control for CM. Drawings should be controlled to ensure they reflect the current configuration of structures, systems, and equipment. Similarly, vendor manuals (or equivalent) used for facility operation should be controlled to ensure they are applicable to installed equipment and contain complete and up-to-date technical information. 
5. A formal process for the preparation, review, and approval of procedures and revisions will be established and maintained. Procedures will be periodically reviewed to ensure continued accuracy and usability.

\section{Requírement Bases:}

A. GPG-FM-012. Paragraph 2.8. Document Control for CM. A formal process should be in place for the preparation, review, and approval of procedures and procedure revisions. Additionally, procedures should be periodically reviewed to ensure continued accuracy and usability.

B. DOE-STD-1073-93. Chapter 1. Section 1.3.1.6. Procedures. After DOE review of the CM program plan, action plans and specific CM implementation procedures consistent with the action plans should be developed. In addition, governing procedures that correlate the implementation procedures with the CM program plan should be developed and maintained. The CM program should include training on $\mathrm{CM}$ concepts, terminology, definitions, and procedures.

6. The configuration-controlled waste inventory shall be used to support required Environmental and Safety reporting.

\section{Requirement Bases:}

A. EIA/S-649, Paragraph 5.6.6, Data Access Control. Effective digital data access fulfills requirements, preserves rights, and provides users with data they are entitled to in the correct version.

B. DOE/RL-93-0106, Annex 4. Paragraph 2.1.4. Waste Inventory Configuration Policy. The TWRS waste inventory configuration shall provide the consistent and approved information needed for the technical planning and engineering required to remediate the tank waste. This inventory configuration used for technology selection and engineering design shall be referenced in the design basis documentation. The following requirements shall apply:

- A waste inventory database shall contain, where available, location, properties (physical, mechanical, thermal), composition (chemical, radiological), and quantity (volume, weight), information. As characterization of the waste proceeds, the approved results shall be added to this database. Where specific properties do not exist, those facts shall be include in the inventory database such that the database shall convey information about what is, and is not known, about the inventory;

- The inventory components shall contain information regarding the date when the component was measured, the source report for the measurement, and the quantity level of the measurement (conceptual estimate or actual physical measurement); 
- Changes to the waste inventory shall be communicated to a controlled distribution to ensure that the appropriate users have up-to-date inventory information;

- All inventory data shall be internally consistent. Database integrity shall be preserved to ensure that data contained therein is entered, changed, or deleted only by authorized personnel and meets all other data protection policies as described in Information Resource Management Policy (Annex 2);

- Changes to the inventory shall be traceable;

- A method shall be established to include projections of future tank waste additions. These projections shall also be subject to configuration control;

- System-generated waste inventory shall be linked to the physical system configuration that produces the waste;

- The configuration-controlled waste inventory shall be used to support required Environmental and Safety reporting.

\subsection{Interface Control}

1. Organizational and technical interfaces will be identified and controlled. For external interfaces (including vendor control), an interface agreement and mutually agreed to documentation of common attributes will be established and maintained. Interface control will be established for internal and external organizational interfaces.

\section{Requirement Bases:}

A. ElA/IS-649 Paragraph 5.2.7, Interface Control. For product interfaces external to the enterprise, establish an interface agreement and a mutually agreed to documentation of common attributes.

B. DOE-STD-1073-93. Chapter 1. Section 1.3.1.4. Interfaces. Establish internal and external (including vendor control) organizational interfaces.

2. Functions, requirements, and physical characteristics of the end product( $(\mathbf{s})$ at common boundaries among project participants, shall be identified, documented, and controlled. For complex projects, Interface Control Working Groups will be established to identify, document, and monitor interfaces. The Interface Control Documents shall be baselined by the appropriate Change Control Board (CCB).

\section{Requirement Bases:}

A. GPG-FM-012, Paragraph 2.3.8, Interface Control. The functions, requirements, and physical characteristics of the end product(s) at common boundaries among project participants need to be identified, documented and controlled. For complex projects, Interface Control Working Groups should be established to identify, document, and 
HNF-SD-WM-CM-016

Rev. 0

September 17, 1997

monitor interfaces. Interface Control Documents should be used to define interfaces, interface responsibilities, and interface requirements in terms of functions, requirements and physical characteristics, as appropriate, and interface constraints and assumptions. For changes that affect functions, requirements and physical characteristics that exist at a common boundary between two configuration items which are controlled by different organizations, the Interface Control Documents should also include interface control drawings.

The Interface Control Documents should be baselined by the appropriate CCB.

B. DOE/RL-93-0106, Annex 4, Paragraph 2.1.2, Technical Baseline Policy. Interface Control Documents (ICDs) are an essential element of Configuration Management. These documents contain the controlled interface information between SSCs. Each SSC document shall contain references to its associated ICDs, where the interfaces to the SSC must be controlled. Likewise, each ICD shall contain references to its associated SSC documents.

\subsection{CHANGE CONTROL}

\subsection{Change Control Process}

1. The TWRS CM program will specify that all requested changes, whether temporary or permanent, to configuration items and information are identified, documented, validated, dispositioned, implemented, and closed. The change is tracked from the point of identification through closure.

\section{Requirement Bases:}

A. DOE-STD-1073-93, Chapter 1, Section 1.3.4.1, Identification of Changes. Within approved CM change mechanisms, each proposed change, including temporary changes and partially implemented changes, should be described sufficiently to support technical reviews, management reviews, and approvals.

B. DOE-STD-1073-93 Chapter 1, Section 1.3.4.5, Documentation of Changes. Each change should be documented and that documentation should include a description of the change, as well as an account of the technical reviews, management approvals, as-built information, and post-modification test results. Documents that are included in the CM program and are affected by a change, either directly or indirectly, should be revised.

2. All mechanisms that can lead to temporary or permanent changes in the TWRS baseline, design requirements, facility configuration, or facility documentation within the $\mathrm{CM}$ program will be identified. These mechanisms will be evaluated to determine which are adequate as is, and which need to be improved, consolidated, or terminated. The resulting change mechanisms will be modified to provide an integrated TWRS change control process that is systematic and measurable. 
HNF-SD-WM-CM-016

Rev. 0

September 17, 1997

\section{Requirement Bases:}

A. EIA/IS-649, Paragraph 5.3. Configuration Change Management Principle. Changes to a product are accomplished using a systematic measurable change process.

B. DOE-STD-1073-93, Chapter 1. Section 1.3.4. Identification of Changes. Identify all . methods that may create a change to design requirements. Evaluate the identified change methods in CM program. Establish controls to sufficiently describe the change to support technical and management reviews and approvals.

C. DOE-STD-1073-93, Chapter 1, Section 1.3.4.1, Identification of Changes All mechanisms that can lead to temporary or permanent changes in the design requirements, facility configuration, or facility documentation within the CM program should be identified. Such mechanisms might include hardware modifications not controlled as projects, hardware modifications controlled as projects, maintenance changes, operational changes, procurement changes, document changes, and computer software changes. Change mechanisms should be evaluated to determine which are adequate as is, and which need to be improved, consolidated, or terminated. The resulting change mechanisms should be integrated with the $\mathrm{CM}$ program.

D. DOE/RL-93-0106, Annex 4, Paragraph 2.2, Configuration Change Control Policy. Changes to the technical baseline shall not be separated and processed outside the overall change control policy. The current status of pending changes shall be available at all times. The overall program change control policy defines pending changes and current status.

3. TWRS change control processes will be integrated and changes coordinated to support the TWRS integrated baseline. Change control is used to maintain consistency and technical accuracy among the requirements, product configuration, and product information as changes are made.

\section{Requirement Bases:}

A. DOE-STD-1073-93, Chapter 1, Section 1.3.4.1. Identification of Changes. All mechanisms that can lead to temporary or permanent changes in the design requirements, facility configuration, or facility documentation within the CM program should be identified. Such mechanisms might include hardware modifications not controlled as projects, hardware modifications controlled as projects, maintenance changes, operational changes, procurement changes, document changes, and computer software changes. Change mechanisms should be evaluated to determine which are adequate as is, and which need to be improved, consolidated, or terminated. The resulting change mechanisms should be integrated with the CM program.

B. DOE-STD-1073-93, Chapter 1, Section 1.3.4, Change Control Element. The objective of the change control element is to maintain consistency among the design requirements, the physical configuration, and the facility documentation as changes are made.

4. The TWRS change control process will establish thresholds for review and approval with the level of management involvement increasing with the importance of the change. 
HNF-SD-WM-CM-016

Rev. 0

September 17, 1997

\section{Requirement Bases:}

A. EIA/IS-649, Paragraph 5.3.1.2. Classifying Changes. Classify requested changes to aid in determining the appropriate levels of review and approval.

B. EIA/IS-649, Paragraph 5.32.4, Change Approval Authority. Change approval decisions are made at an appropriate organizational level with the authority to commit necessary resources to implement the change.

C. DOE-STD-1073-93, Chapter 1, Section 1.3.4, Identification of Changes. Identify all methods that may create a change to design requirements. Evaluate the identified change methods in CM program. Establish controls to sufficiently describe the change to support technical and management reviews and approvals.

5. The change control process is integrated through Change Control Administrators (CCAs), change control boards, and interface control groups. Change control procedures will identify the levels/thresholds for the control of changes affecting technical, cost, and schedule baselines. The change control procedures will describe the change control process and identify responsibilities, forms, and documentation in accordance with these thresholds.

\section{Requirement Bases:}

A. GPG-FM-012, Paragraph 2.3.4. Change Control. Technical baselines should be established and revised by submittal to the appropriate CCB. CCBs provide the coordination necessary to evaluate a change and assess its impact. Within DOE, the assignment of configuration change control responsibilities is generally based on a hierarchy of classes of changes. Change classifications are specified levels established for the control of changes affecting technical, scope, cost, and schedule baselines. To ensure the flow-down of technical requirements, a proposed change to a baseline document, which could affect a higher-level baseline document, should be referred to and acted upon by the higher level CCB first.

B. . DOE/RL-93-0106, Annex 4, Paragraph 2.2, Configuration Change Control Policy. Each program participant shall organize Change Review Boards, or equivalent, to assess the technical impacts of each proposed change at the assigned authority level and recommend disposition of the change.

6. A deviation may be processed in lieu of a change to the baseline when it is necessary to depart from a mandatory design requirement in a specific application but it is not desirable to change the design. Deviations will be minimized and only granted when there is an overriding benefit.

\section{Requirement Basis:}

A. GPG-EM-012. Paragraph 2.3.1.2. Control of Deviations and Waivers. Deviations and waivers are approved exemptions from a particular requirement of the current approved configuration for a specific case or a specified period of time. Deviations relate to variation from approved requirements prior to development or construction of the item; waivers relate to variations after the item has been developed or constructed. Deviations 
HNF-SD-WM-CM-016

Rev. 0

September 17,1997

and waivers differ from approved engineering changes in that they do not require a change to the current approved configuration. Deviations and waivers should be minimized and only granted when there is an overriding benefit. A deviation may be processed in lieu of a change to the baseline when it is necessary to depart from a mandatory design requirement in a specific application but it is not desirable to change the design.

7. A proposed deviation should be converted to a design change if it is determined that the deviation results in a superior design. If an item has departed from specified requirements but is considered suitable for use or for being repaired by an approved method, a waiver should be processed in accordance with applicable procedures.

\section{Requirement Basis:}

A. GPG-FM-012, Paragraph 2.3.1.2. Control of Deviations and Waivers. A proposed deviation should be converted to a design change if it is determined that the deviation results in a superior design. If an item has departed from specified requirements but is considered suitable for use or for being repaired by an approved method, a waiver should be processed in accordance with applicable procedures. The deviation and waiver documents should be maintained as records to show authorization for the as-built condition to vary from the documented design requirements. Waivers may be used on a limited basis to document and approve variations after the item has been developed or constructed.

8. Issuance of a waivers will be followed by an evaluation of the configuration item and requirements to determine the need for a change to the configuration information. When the configuration item and information differ, a change or new configuration information will be processed. Waivers will be minimized and only granted when there is an overriding benefit.

\section{Requirement Basis:}

A. GPG-FM-012, Paragraph 2.3.12. Control of Deviations and Waivers. Deviations and waivers are approved exemptions from a particular requirement of the current approved configuration for a specific case or a specified period of time. Deviations relate to variation from approved requirements prior to development or construction of the item; waivers relate to variations after the item has been developed or constructed. Deviations and waivers differ from approved engineering changes in that they do not require a change to the current approved configuration.

9. Deviations and waivers should be minimized an only granted when there is an overriding benefit. Deviation and waiver documents will be maintained as records traceable to the configuration item and related configuration information to show authorization for the as-built condition to vary from the documented design requirements.

\section{Requirement Basis:}

A. GPG-FM-012, Paragraph 2.3.1.2, Control of Deviations and Waivers. A proposed deviation should be converted to a design change if it is determined that the deviation results in a superior design. If an item has departed from specified requirements but is 
HNF-SD-WM-CM-016

Rev. 0

September 17,1997

considered suitable for use or for being repaired by an approved method, a waiver should be processed in accordance with applicable procedures. The deviation and waiver documents should be maintained as records to show authorization for the as-built condition to vary from the documented design requirements.

\subsection{Change Identification}

Note: There are two major categories of change identification, which include requested change and directed change. Requested change is the need to change the configuration item (product) and directed changes are requested by the customer (e.g., FDH, RL) for items such as directives or budget adjustments. Both change categories must meet the general requirements of the CMProgram and processes.

1. Each change, upon initiation (request and/or identification for need), will be uniquely identified, clearly documented, and tracked via an electronic tracking database. Changes will be submitted on the change form specified by change control procedures. Changes will be defined, reviewed, and approved before implementation.

\section{Requirement Bases:}

A. EIA/IS-649, Paragraph 5.3, Requesting Changes. Changes represent opportunities for improvement.

B. EIA/IS-649. Paragraph 5.3.1. Change Identification. Each change is uniquely identified.

C. EIA/IS-649, Paragraph 5.3.1.2, Documenting Request for Changes. Change request must be clearly documented.

D. GPG-FM-012, Paragraph 2.4.2.1. Change Initiation and Submittal. Proposed change proposals should be submitted on a BCP or equivalent form in accordance with requirements established in project execution planning documentation. Upon receipt of a change proposal, the CCB Secretariat: should review it for completeness; if complete, the Secretariat should log the change proposal, assigning it a unique number; and distribute it to all affected organizations for review and comment.

Proposed changes should be submitted to the appropriate CCB Secretariat (e.g., if initiated by a Field Element, the change proposal would be submitted to the Field Element CCB Secretariat). Proposed change proposals should be submitted on a BCP or equivalent form in accordance with requirements established in project execution planning documentation. Upon receipt of a change proposal, the CCB Secretariat: should review it for completeness; if complete, the Secretariat should log the change proposal, assigning it a unique number; and distribute it to all affected organizations for review and comment.

E. DOE/RL-93-0106, Annex 4, Paragraph 2.2, Configuration Change Control Policy. Each change to the technical baseline and the existing physical configuration must be identified, technically reviewed, dispositioned, implemented (if approved), and properly recorded. 
F. DOE/RL-93-0106, Annex 4, Paragraph 2.2.1, Identification of Changes. All changes to baseline requirements and physical configuration shall be identified and documented. All related changes to SSCs shall be packaged and processed as a single change. All pending and incorporated changes to individual SSCs shall be identifiable and retrievable by the SSC unique identifier. The initiator of a change shall provide sufficient information with the change package to permit the approval authorities to adequately review the proposed change package as described in the following section.

2. A change may be requested by any individual participating in TWRS activities. The initiator will document the change sufficiently to support while processing. Change initiation should include the name of the requester, a description of the proposed change, the affected configuration item and associated configuration item grade, the reason for the change, alternative solutions, due date, constraints and any other information needed for review, tracking, approval and further processing.

\section{Requirement Bases:}

A. GPG-FM-012, Paragraph 2.4.2.1, Change Initiation and Submittal, A change proposal may be initiated by any individual participating in DOE activities. A change proposal identifies affected technical baselines and technical documents.

B. DOE-STD-1073-93, Chapter 1, Part II, Section 2.4.2.1, Identification of Specific Changes. Specific changes should be identified only within established change processes. The need for a potential change may be identified by anyone within the facility and should be documented by the requester to support the processing of the change request.

As defined by the CM program criteria, each proposed change should be described adequately to support technical and management reviews prior to approval. Change initiation should include the name of the requester, a description of the proposed change, the affected SSCs and associated SSC grade, the reason for the change, alterative solutions, due date, and constraints. It should also include any other information needed for review, tracking, approval and further processing.

3. The initiator will perform an initial evaluation of the potential impact of the proposed change. This initial evaluation will identify, to the extent possible, baselines (technical, cost, and schedule), configuration items, configuration information, and documentation, which need to be updated to reflect the proposed change.

\section{Requirement Bases:}

A. GPG-FM-012, Paragraph 2.4.2.1. Change Initiation and Submittal. The initiator should perform an initial evaluation of the potential impact of the proposed change. This initial evaluation should identify, to the extent possible, all documents and data bases which need to be updated to reflect the proposed change.

B. DOE/RL-93-0106, Annex 4, Paragraph 2.2.2. Technical Change Reviews. Each change shall be reviewed to: 
- Verify that the technical impact of the change is completely known. This includes design, performance, interfaces, reliability, maintainability, environmental, safety, logistics, support, and mission impacts.

- Verify that all impacted SSCs and documents are identified and that the change package includes all appropriate change documentation for each affected SSC.

- Ensure that the appropriate implementation and acceptance criteria are identified and that the implementation of the change is technically acceptable. When establishing a change, the MEL shall be consulted to ensure that the change does not conflict with a configuration nonconformance that may cause a hazard or safety violation. The change package shall specify change implementation and acceptance criteria.

4. The proposed change will be described sufficiently to support technical and management reviews and dispositioning by management.

\section{Requirement Basis:}

A. GPG-FM-012, Paragraph 2.4.2.1, Change Initiation and Submittal. A change proposal may be initiated by any individual participating in DOE activities. A change proposal identifies affected technical baselines and technical documents. The initiator should perform an initial evaluation of the potential impact of the proposed change. This initial evaluation should identify, to the extent possible, all documents and databases which need to be updated to reflect the proposed change. Before submittal for approval, the change request package will document (level of detail may vary depending on importance and complexity of the change):

\section{- Unique change identifier}

- Originator organization and responsible individual

- Level of change

- Baselines, configuration items, configuration information, and interfaces affected

- Contract and configuration documents affected

- Scope and description of change, including work efforts

- Benefit of the change

- Estimated cost increase/decrease of the change and identification of associated WBS element

- Effects on specified performance, operation, maintenance, servicing, operation and maintenance training, spare and repair parts, support and test equipment, catalogs, marketing literature, etç. 
HNF-SD-WM-CM-016

Rev. 0

September 17, 1997

- Reason and justification for the change; consequences of not doing the change

- Priority/urgency of the change

- Proposed change affectivity (time period and conditions under which the change will occur)

- Requested approval date

- Change implementation and delivery schedules

- Estimated cost increase or savings

- Alternatives

- Reviewer comments and comment resolutions.

5. Before submittal for approval, the change request package will document (level of detail may vary depending on importance and complexity of the change):

- Unique change identifier

- Originator organization and responsible individual

- Level of change

- Baselines, configuration items, configuration information, documents, and interfaces affected

- Contract and configuration documents affected

- Scope and description of change, including work efforts

- Benefit of the change

- Estimated cost increase/decrease of the change and identification of associated WBS element

- Effects on specified performance, operation, maintenance, servicing, operation and maintenance training, spare and repair parts, support and test equipment, catalogs, marketing literature, etc.

- Reason and justification for the change; consequences of not doing the change

- Priority/urgency of the change

- Proposed change affectivity (time period and conditions under which the change will occur) 
HNF-SD-WM-CM-016

Rev. 0

September 17, 1997

- Requested approval date

- Change implementation and delivery schedules

- Estimated cost increase or savings

- $\quad$ Alternatives

- Reviewer comments and comment resolutions.

\section{Requirement Bases:}

A. EIA/IS-649, Paragraph 5.3.1.3, Documenting Requests for Changes. Change requests must be clearly documented. To adequately evaluate a request for change, the change request must be clearly documented. It is important to accurately describe even minor changes so that an audit trail can be constructed in the event that there are unanticipated consequences or unexpected product failures. Saving the cost to the research involved in on such incident by having accurate accessible records may be sufficient to fully offset diligent, disciplined change processing.

Documentation or major changes includes the following information that is required to make a informed evaluation of the change and to clearly define the change:

- Unique change identifier

- Originator organization and responsible individual

- Class of change

- Product(s), major components, interfacing products affected

- Contract and configuration documents affected

- Scope and description of change, including work efforts

- Effects on specified performance, operation, maintenance, servicing, operation and maintenance training, spare and repair parts, support and test equipment, catalogs, marketing literature, etc.

- Reason and justification for the change; consequences of not doing the change

- Priority/urgency of the change

- $\quad$ Proposed change affectivity

- Requested approval date

- Change implementation and delivery schedules 
HNF-SD-WM-CM-016

Rev. 0

September 17, 1997

- Estimated cost increase or savings

- Alternatives.

Minor changes are documented in the format used to release and communicate design changes. As a minimum, the following information is necessary:

- Unique change identifier

- Originator organization and responsible individual

- Class of change

- Product, assemblies, and components affected

- Configuration documents affected

- Description of change

- Reason for the change

- Proposed change affectivity.

B. GPG-FM-012. Paragraph 2.4.2.1, Change Initiation and Submittal. A change proposal may be initiated by any individual participating in DOE activities. A change proposal identifies affected technical baselines and technical documents. The initiator should perform an initial evaluation of the potential impact of the proposed change. This initial evaluation should identify, to the extent possible, all documents and data bases which need to be updated to reflect the proposed change. Additionally, the proposed change should be evaluated to ensure that adequate justification is provided for making the change and that the proper technical approach is described.

C. DOE-STD-1073-93, Chapter 1, Part II, Section 2.42.1, Identification of Specific Changes. As defined by the $\mathrm{CM}$ program criteria, each proposed change should be described. Adequately to support technical and management reviews prior to approval.

D. GPG-FM-012, Paragraph 2.4.2.2, Change Review and Impact Evaluation. Affected organizations should review and evaluate the proposed change to determine if: (1) the change is necessary, (2) the technical approach is adequate and complete, and (3) the technical, scope, cost and schedule impacts are identified. The cognizant CCB Secretariat should compile and coordinate comment resolution and distribute a change package for review by the $\mathrm{CCB}$ members prior to $\mathrm{CCB}$ disposition. The change package should include, as a minimum, the change proposal, reviewers comments and comment resolutions.

The technical approach should be reviewed for adequacy and completeness of necessary changes. Additionally, the evaluation should review the proposed change to ensure compliance with the technical baseline and identify the documents and data bases (e.g., 
design criteria, training, and interface documents), for which they have responsibility, which are affected by the proposed change. This information is included as part of the change package. This evaluation should also include reviews for impact on cost and schedule baselines.

The estimated cost of each change should be identified with the appropriate WBS element(s). Supporting cost data at the next-lower level of the WBS should be supplied to relate the significant cost elements to the principal elements of the proposed change.

6. Prior to approval, the change package will identify the baselines, configuration items, configuration information, and documents to be modified or affected by the change.

\section{Requirement Basis:}

A. DOE-STD-1073-93. Chapter 1. Part II. Section 2.4.2.1, Identification of Specific Changes. As defined by the CM program criteria, each proposed change should be described adequately to support technical and management reviews prior to approval. Directed changes by the customer provide direction to change technical, schedule and/or cost baselines.

7. Directed changes will be processed to identify impacts, determine how they can best be implemented, generate implementing change proposals, and respond to the customer regarding these items.

\section{Requirement Basis:}

A. GPG-FM-012, Paragraph 2,4,2,4. Directed Changes. For directed changes, such as DOE directives or budget adjustments, the directive is the authorization for implementing the change. However, the baseline change control process should be followed to ensure all impacts of the directed change are identified. The responsible Program Office manager should forward a copy of the directive to the responsible Field Element manager. The Field Element manager should prepare and process a BCP for the directed change in accordance with the guidelines of this section.

\subsection{Change Evaluation and Coordination}

1. Proposed changes to each TWRS baseline component (technical, schedule, and cost) will be evaluated for impacts. Proposed changes will be routed to and evaluated by affected organizations to determine whether:

- There is adequate justification for the change and the change is necessary

- There is a benefit for the change

- The technical approach is adequate and complete

- The technical, cost, and schedule impacts are correctly identified. 
HNF-SD-WM-CM-016

Rev. 0

September 17, 1997

\section{Requirement Bases:}

A. ElA/IS-649, Paragraph 5.3,1,2, Classifving Changes. Classify requested changes to aid in determining the appropriate levels of review and approval.

B. EIA/IS-649, Paragraph 5.3.2, Change Evaluation and Coordination. Consider the technical, support, schedule, and cost impacts of a requested change before making a judgement as to whether the change should be approved for implementation and incorporation in the product and its documentation.

C. EIA/S-649, Paragraph 5.3.2.1, Change Impact Assessment. Determine all potential effects of a change and coordinate potential impacts with the impacted areas of responsibility.

D. EIA/IS-649, Paragraph 5.3.2.2. Change Effectivity Determination. Change documentation delineates which unit(s) of the product are to be changed. Change affectivity includes both production break-in and retrofit/recall, as applicable. A changed product should not be distributed until support and service areas are able to support it.

E. EIA/IS-649 Paragraph 5.3.2.3, Change Cost/Price Determination. The decision maker is aware of all cost factors in making the decision.

F. GPG-FM-012, Paragraph 2.4.2.1, Change Initiation and Submittal. Additionally, the proposed change should be evaluated to ensure that adequate justification is provided for making the change and that the proper technical approach is described.

G. GPG-FM-012, Paragraph 2.42.2. Change Review and Impact Evaluation. Affected organizations should review and evaluate the proposed change to determine if: (1) the change is necessary, (2) the technical approach is adequate and complete, and (3) the technical, scope, cost and scheduie impacts are identified. The cognizant CCB Secretariat should compile and coordinate comment resolution and distribute a change package for review by the $\mathrm{CCB}$ members prior to $\mathrm{CCB}$ disposition. The change package should. include, as a minimum, the change proposal, reviewers comments and comment resolutions.

The technical approach should be reviewed for adequacy and completeness of necessary changes. Additionally, the evaluation should review the proposed change to ensure compliance with the technical baseline and identify the documents and data bases (e.g., design criteria, training, and interface documents), for which they have responsibility, which are affected by the proposed change. This information is included as part of the change package. This evaluation should also include reviews for impact on cost and schedule baselines.

The CCB evaluation addresses the options of making or not making the proposed change: Changes should be limited to those that:

- correct deficiencies, including safety deficiencies; 
- offer a significant improvement in performance or functionality;

- effect substantial capital and life-cycle cost savings;

- prevent slippage in an approved schedule; or

- implement approved changes to other portions of the scope, cost, and schedule baselines or the DOE Strategic Plan.

Projects within existing operating facilities and projects in the execution phase should perform technical reviews.

H. DOE-STD-1073-93, Chapter 1. Section 1.3.4. Change Control Element. The objective of the change control element is to maintain consistency among the design requirements, the physical configuration, and the facility documentation as changes are made.

2. Each proposed change to design requirements will be evaluated and approved by the design authority before implementation.

\section{Requirement Bases:}

A. DOE-STD-1073-93, Chapter 1, Section 1.3.4.2. Technical Review of Changes. Each specific proposed change should be reviewed to determine if it is within the bounds of the design requirements. Changes to the design requirements should be evaluated and approved by the design authority prior to implementation. The technical reviews should evaluate safety, environmental, and mission impacts; determine appropriate post-implementation acceptance criteria; and identify the affected SSCs and facility documentation.

B. DOE-RL-93-0106, Annex 4, Paragraph 2.2.3, Technical Change Approval Levels. The $\mathrm{DOE}$ and $\mathrm{M} \& \mathrm{O}$ Contractor, and Engineering Contractors shall retain change approval authority at the same level as their release authority. (See Section 2.1.2)

3. Technical reviews will evaluate safety, environmental, and mission impacts; determine appropriate post-implementation acceptance criteria; and identify the affected SSCs and facility documentation. These technical reviews will verify the compatibility of a change with facility design and ensure that the proposed change does not adversely affect facility safety, reliability, or operation.

\section{Requirement Bases:}

A. GPG-FM-012, Paragraph 2.7. Technical Reviews. The technical review of a proposed change to facility design, facility test; or facility procedures should evaluate the overall effect of the change on the existing facility (e.g., design and operation). The technical review program should include the formal process of reviewing, confirming, or substantiating the adequacy of a change. Quality Assurance Requirements, should be incorporated into the baseline reconstitution program. 
These requirements should be applied to review of new projects, tests, and procedures as appropriate. Technical reviews verify the compatibility of a change with facility design and ensure that the proposed charige should not adversely affect facility safety, reliability, or operation.

B. DOE/RL-93-0106, Annex 4, Paragraph 2.2.2. Technical Change Reviews. Upon completion of the technical review of the change, the Change Package shall be dispositioned regarding its acceptability and processed in accordance with the policy prescribed in Business Management Policy (Annex 1). Each Change Package shall be tracked until the change is completely incorporated into the SSCs and their affected documents, or into the documents if the change does not affect an SSC.

4. Coordination of a change request will be the responsibility of the project manager that the change is affecting. For baseline changes, after submittal to the $\mathrm{CCB}$, the Change Control Administrator is responsible for coordinating the changes final disposition and returning it to the affected project manager for implementation and closure.

\section{Requirement Bases:}

A. EIA/IS-649, Paragraph 5.3.2. Change Evaluation and Coordination. Consider the technical, support, schedule, and cost impacts of a requested change before making a judgement as to whether the change should be approved for implementation and incorporation in the product and its documentation.

B. EIA/IS-649 Paragraph 5.3.2.1. Change Impact Assessment. Determine all potential effects of a change and coordinate potential impacts with the impacted areas of responsibility.

\subsection{Change Disposition}

1. Before dispositioning, proposed changes will be reviewed by management to verify that the other reviews have been performed adequately, that the change package is complete and ready for implementation, and that any external approvals necessary before implementation have been obtained.

\section{Requirement Basis:}

A. DOE-STD-1073-93. Chapter 1. Section 1.3.4.3, Management Review of Changes. Before implementation, management should review proposed changes (including those that do - not involve a change to design requirements) to verify that the technical reviews have been performed adequately, that the change package is complete and ready for implementation, and that any external approvals necessary prior to implementation have been obtained. On the basis of these reviews, management should take approval action.

2. Proposed changes will be dispositioned (e.g., canceled/withdrawn, deferred, disapproved, approved with conditions, or approved) by the applicable authority. 


\section{Requirement Basis:}

A. GPG-FM-012.Paragraph 2.4.2.3, Change Disposition. Proposed changes may be canceled/withdrawn, deferred, disapproved, approved with conditions, or approved by the applicable CCB. The CCB Chairperson should have full decision making authority as the $\mathrm{CCB}$ is an advisory, not a voting board. In their advisory capacity and for their individual. areas of technical responsibility and expertise, each board member assures the chairperson that everything has been addressed that should be addressed. At the discretion of the CCB Chairperson, change proposals may be dispositioned without conducting a board meeting. Only those changes that are approved changes or approved with conditions should be implemented. Proposed changes may be canceled/withdrawn by the originator with $\mathrm{CCB}$ approval.

\subsection{Change Implementation and Verification .}

1. Management will review change proposals to verify that adequate reviews have been performed, the change package is complete and ready for implementation, and required external approvals are obtained before implementation. Approved changes will be implemented in accordance with documented direction approved by the appropriate authority.

\section{Requirement Basis:}

A. EIA/IS-649 Paragraph 5.3.3. Change Implementation and Verification. Implement an approved change in accordance with documented direction approved by the appropriate level of authority.

2. Revisions to the approved change proposal shall, as a minimum, be subject to the same requirements applied to the initial change proposal.

\section{Requirement Basis:}

A. GPG-FM-012. Paragraph 2.4.2.5 Change Implementation. Implementation of changes may include physical changes in addition to documentation changes. Change implementation involves the following considerations:

If the change proposal requires physical implementation, it should be completed using the Field Element work plan process. Revisions to the approved change proposal required during physical implementation should be subject to the same requirements applied to the initial request.

3. Limits shall be established for the maximum number of outstanding changes that can exist against a given configuration item or information and the maximum time between approval or implementation of the change and incorporation into the affected configuration information. 
HNF-SD-WM-CM-016

Rev. 0

September 17, 1997

\section{Requirement Basis:}

A. GPG-FM-012, Paragraph 2.4.2.5 Change Implementation. Implementation of changes may include physical changes in addition to documentation changes. Change implementation involves the following considerations:

- Upon completion and acceptance of the physical change (or after approval of the change proposal if no physical implementation is required) affected documents and data bases should be updated in a timely manner but, not until the physical implementation has been completed and accepted

- Limits should be established for the maximum number of outstanding changes which can exist against a given document and the maximum time duration between approval or implementation of the change and incorporation into the affected documents. Typical limits for documents not required by operators are 5 changes or 6 months.

- Field Element procedures should establish responsibilities for physical implementation of changes, updating affected documents and databases, and verification of completion of the change. The implementing organization(s) should verify that necessary action is completed within the time frames set forth in the change authorization document.

4. All changes will be closed in accordance with the disposition of the change. If closure of the change or part of the change does not take place or within the effectivity date identified on the approved change, further change processing is required to cancel, revise, or supersede the change so that actual implementation and closure status is reflected. If any portion of the change request has been implemented, the change request cannot be canceled. Change closeout does not occur until:

- The configuration item change or configuration information change has been completed, tested (physical changes), and accepted

- All affected configuration information has been updated to correctly reflect the change

- Any necessary training has been completed.

\section{Requirement Basis:}

A. GPG-FM-012, Paragraph 2.4.2.7. Change Closeout. Change closeout should not occur until: (1) the physical change or technical document change has been completed, tested (physical changes), and accepted; (2) all affected documents and data bases have been updated to correctly reflect the change, (3) any necessary training has been completed. Upon completion of implementation, verification, acceptance and training, change implementation should be verified to ensure each implemented change is complete and in compliance with the approved change documents. After verification is complete, the CCB Secretary should be notified for update of the BCCB log. The change proposal or BCP 
HNF-SD-WM-CM-016

Rev. 0

September 17, 1997

should be closed and submitted as a record in accordance with approved records management procedures.

5. The TWRS CM program shall ensure that changes are implemented in accordance with the approved change package and that, when all approved changes are completed, they are reviewed, inspected, and (if required) tested to determine if the change meets its post-implementation acceptance criteria. Impacted configuration information will be revised (e.g., as-built) to incorporate related change information.

\section{Requirement Bases:}

A. DOE-STD-1073-93, Chapter 1, Section 1.3.4.4, Implementation of Changes Each change should be implemented in accordance with its approved change package. The change process should include mechanisms for field change requests, and technical reviews and approvals of field changes should be commensurate with those of the original change package. The change process should generate accurate as-built information. After the physical implementation of changes, post-modification testing should be conducted.

B. DOE-STD-1073-93, Chapter 1, Section 1.3.4.5, Documentation of Changes. Each change should be documented and that documentation should include a description of the change, as well as an account of the technical reviews, management approvals, as-built information, and post-modification test results. Documents that are included in the CM program and are affected by a change, either directly or indirectly, should be revised.

\subsection{CONFIGURATION STATUS AND ACCOUNTING}

\subsection{Status of Product/System}

1. Configuration information (e.g., engineering documents, database content) and changes to that information will be processed and recorded to maintain a continuous record of the selected baseline. Configuration status accounting will provide accurate and timely information about the baseline to management, CCAs, schedulers, and others to facilitate effective management of work.

\section{Requirement Bases:}

A. EIA/S-649, Paragraph 5.4, Configuration Status Accounting. An accurate timely information base concerning a product and its associated product information is required throughout the product life-cycle.

B. GPG-FM-012. Paragraph 2.3.1.3, Waste Inventory Configuration. Where applicable, waste inventory should be controlled in a manner similar to the technical baseline. The inventory configuration should provide the consistent and approved information needed for the technical planning and engineering required to remediate the waste. This inventory configuration used for technology selecting and engineering design should be referenced in the design basis documentation.

C. DOE-STD-1073-93, Chapter 1, Section 1.3.6.2, Paragraph a. Identification and Retrieval of Design Information. The objective and scope of source documents to be reviewed 
should be defined for each document identification and retrieval stage. The recommended stages are the formal review, the smart search, and the comprehensive search. The formal review should address those on-hand documents, such as the facility safety analysis and TSRs, that contain summary-type design information; the smart search should identify and retrieve those types of documents that can be identified as most likely to contain design requirements; and the comprehensive search should identify and retrieve any remaining documents that might contain design information, including DOE correspondence and vendor correspondence.

D. DOE-STD-1073-93. Chapter 1, Section 1.3.6.5, Regeneration of Missing Critical Design Information. Missing design information should be evaluated to determine which part needs to be regenerated. Missing design information that is critical, inciuding that necessary to support the facility accident analysis and TSRs, should be regenerated in order of priority.

E. Lockheed Martin Corporation, CPS-422, Configuration Management, Paragraph 2.6. Establishing and maintaining a status accounting and reporting system which records the technical documentation baseline, authorized changes to the baseline, and verification of change incorporation into the documentation and/or product.

2. Configuration status accounting system records and reports shall include the identification and retrieval of configuration information, listing of the approved information, the status of change proposals, and how effectively approved changes are being implemented. The status of configuration is determined, tracked, trended, and made available to users.

\section{Requirement Basis:}

A. DOE-STD-1073-93, Chapter 1, Section 13.6.2, Paragraph b. Identification and Retrieval of Design Information. Technical review and identification of design information from each source document should include both design requirements and design basis information. Extracted design information should be identified as to the applicable facility $\mathrm{SSC}_{s}$ type of SSC, technical topic area, and whether it is a design requirement or design basis. The technical review and identification of design information from each source document should be complete, such that the document does not have to be reconsidered during subsequent searches and review.

\subsection{CONFIGURATION VERIFICATION AND AUDIT}

\subsection{Design and Document Verification}

1. Physical configuration assessments, or walkdowns, will be performed for representative configuration items to determine the degree of agreement between the physical configuration and the configuration depicted in the specification requirements and other documentation. Physical walkdowns will be included as part of the programmatic assessments and periodic effectiveness assessments. If substantive discrepancies (either in number or type) are discovered, appropriate immediate corrective actions shall be developed to establish agreement between the physical configuration and the documentation. 
HNF-SD-WM-CM-016

Rev. 0

September 17, 1997

\section{Requirement Bases:}

A. DOE-STD-1073-93, Chapter 1, Section 1.3.5.2, Physical Configuration Assessments. Perform field verification assessments on representative SACS to determine the accuracy of $\mathrm{CM}$ documentation with the hardware that the documentation depicts. Establish a corrective action process to align discrepant conditions. Corrective actions shall include characterization and qualification of problem and design verification necessary to validate the discrepancy.

Physical configuration assessments, or walkdowns, should be performed for representative sample SSCs to determine the degree of agreement between the physical configuration and the configuration depicted in the facility documentation. Physical walkdowns should be included as a part of the programmatic assessments, and periodic effectiveness assessments. If substantive discrepancies (either in number or type) are discovered, appropriate immediate corrective actions should be developed to establish agreement between the physical configuration and the documentation. The corrective actions should include additional walkdowns to characterize the problem and to determine the extent of the problem. They should also include technical evaluations to determine whether the physical configuration or the documentation should be changed.

B. DOE-RL-93-0106, Annex 4, Paragraph 2.3. Assessments Policy. Assessment and surveillance results and corrective actions shall be submitted to the TWRS Program Office if the DOE or an agency external to DOE requests the assessment or surveillance; or as prescribed in Quality Management Policy (Annex 6).

C. Lockheed Martin Corporation, CPS-422, Configuration Management, Paragraph 2.3 Implementing a method for verifying accomplishment of specification requirements.

2. Measures will be established for an item within the CM program to be tested after modification (and before being turned over for service) to determine whether it is capable of meeting its design requirements (i.e., the post-implementation acceptance criteria). If a changed item fails to meet its post-implementation acceptance criteria, turnover for operation will be postponed until either a technical review has been completed and any follow-up actions are completed, or until the item is retumed to its original condition and tested satisfactorily.

\section{Requirement Bases:}

A. DOE-STD-1073-93, Chapter 1. Section 1.3.5.4, Post-Modification Testing. An SSC within the CM program should be tested after modification (and before being turned over for service) to determine if it is capable of meeting its design requirements (i.e., the post-implementation acceptance criteria). If a changed SSC fails to meet its post-implementation acceptance criteria, turnover for operation should be postponed until either a technical review has been completed and any follow-up actions are completed or until the SSC is returned to its original condition and tested satisfactorily.

Perform SSC testing subsequent to modification to ensure compliance with design requirements prior to turnover for service. 


\section{B. Lockheed Martin Corporation, CPS-422, Configuration Management, Paragraph 2.3. Implementing a method for verifying accomplishment of specification requirements.}

3. Appropriate design validation measures will be taken and documented to substantiate that extracted design information will be verified by a second party to ensure that the design information is extracted completely and accurately from the source documents. Extracted design information shall be technically validated to ensure that it is reasonable, that it is applicable to the current facility mission and configuration, and that the analytical methods and technical assumptions used in the design process are valid and appropriate. Design basis information shall be correlated with the design requirements.

\section{Requirement Bases:}

A. EIAIIS-649, Paragraph 5.5 Configuration Verification and Audit. Verification that a product's requirement attributes have been met and the product design meeting those attributes has been accurately documented is required to baseline the product configuration.

B. EIA/IS-649, Paragraph 5.5.1 Configuration Verification and Audit. Verification that a design achieves its goals is accomplished by a systematic comparison of requirements with the results of tests, analyses or inspections. Documentation of a product's definition must be complete and accurate enough to permit reproduction of the product without further design effort.

C. EIA/IS-649, Paragraph 5.5.2 Configuration Verification and Audit. When necessary, verification is accomplished by configuration audit.

D. DOE-STD-1073-93, Chapter 1, Section 1.3.6.3. Evaluation, Verification, and Validation of Design Information. Extracted design information should be verified by a second party to ensure that the design information was extracted completely and accurately from the source documents. Extracted design information should be technically validated to ensure that it is reasonable, that it is applicable to the current facility mission and configuration, and that the analytical methods and technical assumptions used in the design process are valid and appropriate. Design basis information should be correlated with the design requirements. Extracted design information should also be evaluated to identify any missing design requirements or design basis information. Design Information Summaries should be field validated to ensure that design requirements are properly reflected in the physical configuration and in the associated facility documentation.

4. Periodic maintenance of configuration items will be performed to address surveillance, in-service inspection, and testing to ensure that equipment continues to meet design requirements.

Monitoring shall include aging degradation of equipment, as determined by the material condition and aging program. Monitoring shall include measurements and trending of data related to the actual aging degradation of equipment. 
HNF-SD-WM-CM-016

Rev, 0

September 17, 1997

\section{Requirement Bases:}

A. DOE-STD-1073-93, Chapter 1, Section 1,3.5.3 Periodic Equipment Performance Monitoring. Perform periodic maintenance of SSCs to address surveillance, In-service inspection, and testing to ensure that equipment continues to meet design requirements. Monitoring shall include aging degradation of equipment as determined by the material condition and aging program. Structures, systems, and components (SSCs) within the CM program should be tested periodically to determine if they are still capable of meeting their design requirements. This monitoring should also address surveillance actions, periodic in-service inspections and tests, and other monitoring of SSCs to ensure safe and reliable operation of the facility. Monitoring should aiso include measurements and tending of data related to the actual aging degradation of equipment, to the extent identified by the MCA adjunct program an approved by the design authority.

B. DOE-RL-93-0106, Annex 4, Paragraph 2.3.3, In-Service Inspection Testing. SSCs meeting established minimum grade levels shall be inspected and tested on a scheduled basis to determine the current configuration status. In-service inspection testing shall be performed in conjunction with the maintenance and operations functions to combine work and records where possible. The M\&O Contractor shall establish the minimum SSC grade levels, and the in-service inspection and testing shall be preformed in accordance with nuclear industry standards.

C. DOE-RL-93-0106, Annex 4, Paragraph 2.4.2, Management of Material Condition and Aging. A Material condition and Aging program shall perform the following activities for selected critical SSCs:

- Assess the material condition of potentially life-limiting components of a facility;

- Estimate the remaining life span of the SSCs;

- Develop analytical and periodic testing procedures to measure aging degradation trends;

- Evaluate the feasibility of continued and extended operations. If extension is feasible, develop techniques to extend the life span of the SSCs.

\subsection{Continuing Performance Audits and Surveillance}

1. Periodic assessments will be performed to evaluate the adequacy of the configuration management program and products. Weaknesses within the program will be identified and deficiencies reported and tracked to resolution.

\section{Requirement Bases:}

A. GPG-FM-012, Paragraph 2.3.11, Reviews. Assessments should be performed to measure the effectiveness of the configuration management process, and consistency between the project physical system and the documentation that represents that system. Contractor 
assessment and surveillance results and corrective actions should be reviewed by the Field Element.

B. DOE-STD-1073-93, Chapter 1, Section 1.3.5.1, Paragraph a Programmatic Assessments. During the planning for the CM program, initial assessments should be conducted to determine the strengths and weaknesses of existing programs and procedures with regard to determining where upgrade actions and resource investments are necessary. Two vertical slice assessments relevant to the facility should be conducted. One of these should be on a safety system related to the principal facility hazard, either nuclear or non-nuclear. Two horizontal slice assessments relevant to the facility should also be performed. One of these should be on change control and the other on a technical topical area, such as seismic qualifications or fire protection.

C. DOE-STD-1073-93, Chapter 1, Paragraph b, Section 1.3.5.1 Post-Implementation Assessments. After the CM program upgrades are implemented, a horizontal slice assessments should be performed for each $\mathrm{CM}$ program element to determine if that element addresses identified weaknesses and is effective in accomplishing the CM functions. For each system design information summary (DIS) developed by the DR adjunct program, a field validation should be performed to ensure that the design requirements are accurately reflected in the physical configuration and the associated facility documentation. After the MCA adjunct program is developed, a technical quality review should be performed of its assumptions, methods, and products.

\section{DOE-STD-1073-93, Chanter 1, Section 1.3.5.1, Paragraph c, Periodic Effectiveness} Assessments. After the CM program and its adjunct programs have been implemented, a combination of vertical and horizontal slice assessments should be performed periodically to measure the overall $\mathrm{CM}$ program effectiveness and to determine if $\mathrm{CM}$ controls are adequate and appropriate. The results of these assessments should establish the basis for revisions to the CM program plan, either increasing or decreasing controls.

E. Lockheed Martin Corporation, CPS-422, Configuration Management, Paragraph 2.7. Managing configuration audits as required by contract and the applicable policies and procedures.

F. Lockheed Martin Corporation, CPS-422, Configuration Management Paragraph 3.2.3. Evaluate current and new programs to determine the appropriate level of configuration management requirements.

\subsection{GLOSSARY}

\section{As-Built}

Documentation (for example, Piping and Instrument Diagrams, and database records) verified by physical inspection as depicting the actual physical configuration and verified as consistent with the design requirements. 
HNF-SD-WM-CM-016

Rev. 0

September 17, 1997

\section{Assessments}

CM program element that encompasses the following functions: conducting programmatic and physical configuration assessments, performing periodic equipment performance monitoring, and performing post-modification testing.

\section{Baseline}

A set of documented decisions that constitutes an established reference position for control, status accounting, reviews, assessments, and changes. These decisions are delineated in selected technical and programmatic documents that are identified and controlled. Baselines are continually changing via an orderly control of changes as required in DOE-HQ, RL, and the configuration management programs, especially during the development phase. Therefore, the current baseline is always the previously approved baseline with all approved changes.

\section{Basis}

The basis is the full set of information used to establish a function, requirement, or baseline. The basis explains why a function, requirement, or baseline has been specified in a particular manner or as a particular value. The basis consists of the inputs, constraints (e.g., regulations), analysis, studies, and calculations. The basis includes that subset that relates to safety and the authorization basis.

\section{Change}

Any alteration or addition, temporary or permanent, to a product. Changes not within current design requirements involve design changes. For system, structure, or components, identical replacements are not changes.

\section{Change Classification}

A system of classifying changes for Site programs and projects, based on the threshold criteria and approval requirements identified in this document.

\section{Change Control}

A process that ensures all changes are properly identified, reviewed, approved, implemented, tested, and documented.

\section{Change Control Administrator}

The person responsible for processing proposed changes and maintaining the database that tracks change requests and change request status. 


\section{Change Board}

A board composed of technical and administrative representatives who review, approve, disapprove, or defer changes to a product (e.g., an approved cost, schedule, or technical baseine). These boards may be established by the PHMC program, contractors, or individual projects.

\section{Change Request}

The document used to initiate changes to approved configuration information (e.g., program cost, schedule, and technical baselines) and uniquely identified by a change identification number. The change request is used to document change proposals that require dispositions by the appropriate Change Control Board member.

\section{Common Attributes}

Functions, requirements, products, and/or information shared by two or more interfacing entities or items.

\section{Computer Software}

A set of computer source codes and/or commercial software, with the procedures, rules, and associated documentation and data pertaining to the operation of computer systems and includes user-provided instructions and data that implement pre-programmed algorithm control systems; computer codes and data that will reside in firmware; and, when specified by the cognizant manager, user-provided instructions and data used by commercial computer software such as spreadsheet and database packages.

\section{Configuration}

The functional and/or physical characteristics as delineated in configuration information and achieved in a configuration item (form, fit, and function).

\section{Configuration Item}

A product that has been selected to be controlled and for which the configuration and configuration information (including basis) will be managed. (Example: A doorknob may be a product but is not controlled and consequently is not considered a configuration item. A disposal tank is a more important product and is controlled as a configuration item.)

\section{Configuration Item Scope Criteria}

The specific selection standards used to choose which products will be controlled.

\section{Configuration Information}

Data and documentation that defines, provides basis for, or otherwise has an important relationship to a product and is controlled to maintain that relationship. 
HNF-SD-WM-CM-016

Rev. 0

September 17,1997

\section{Configuration Information}

Information (includes documents) that defines or supports a configuration item and has been selected to be managed.

\section{Configuration Management}

An integrated management program used to established consistency among requirements, basis, functional configuration, and documentation, and maintains this consistency throughout the life of the product as changes occur.

\section{Design Basis}

The design basis is the full.set of information used to establish a design. The design basis explains why a design requirement has been specified and a particular manner or as a particular value. The design basis consists of the design inputs, design constraints, design analysis, and calculations. It includes topical areas such as seismic qualification, fire protection, and safe shutdown. The design basis encompasses consideration of factors such as availability, efficiency, costs, and maintainability, and that subset that relates to safety and the authorization basis.

\section{Design Reconstitution}

An adjunct program to the configuration management program that accomplishes the one-time effort of identifying, retrieving, extracting, evaluating, verifying, validating, and regenerating missing critical design requirements and basis. Design reconstitation encompasses the following functions: developing associated program plans and procedures; identifying and retrieving design information from identified source documents; evaluating, verifying, and validating the design information; resolving discrepancies; regenerating missing critical design information; and preparing and issuing Design Information Summaries.

\section{Design Requirements}

Those requirements reflected in design output documents (such as drawings and specifications) that define the functions, capabilities, capacities, physical sizes, limits and setpoints, etc., specified by design engineering for a structure, system, or component. The design requirements provide the results of the design process.

\section{Design Review}

An evaluation of structure, system, and component designs to ensure that requirements and considerations (both normal and emergency) of electrical, mechanical, thermal, hydraulic, safety, producability, reliability, maintainability, quality, inspectability, interfaces, engineering standards, design, and fabrication practices are met for the intended application.

\section{Design Validation}

A comprehensive testing of information, data, and procedure contained in the design of the product. The technical data product is tested for technical adequacy, accuracy, and compliance 
HNF-SD-WM-CM-016

Rev. 0

September 17, 1997

with the provisions of the specification and other contractual requirements. Validation is accomplished by comparing the data product with the actual systems or equipment for which the data product was prepared.

\section{Deviation}

An approved exemption from a particular requirement of the current approved configuration for a specific case or a specified period of time. Deviations relate to variation from approved requirements before development or construction of the item. Deviations differ from approved engineering changes in that they do not change the current approved configuration.

\section{Directed Changes}

Directed changes are changes required by the customer, including any alteration or addition, temporary or permanent, to the facility physical configuration, facility documentation, or design requirements. These changes include direction to change technical, schedule, and/or cost baselines.

\section{Documents}

Any electronic, text-type, or pictorial information.

\section{Document Control}

A process that stores and controls, tracks status (especially during revisions), and retrieves documents.

\section{Engineering Documents}

Any electronic, text-type, or pictorial information that describes, defines, specifies, reports, or certifies activities, requirements, procedures, or results of engineering activities and contains engineering and technical information that communicates concepts, plans, descriptions, criteria, requirements, standards, and instructions.

\section{Engineering Drawing}

A document that depicts by means of graphics, pictorial, and/or textual presentation the form, fit, and function requirements of item(s).

\section{Graded Approach}

A process by which the level of analysis, documentation, and actions necessary to comply with the requirement are made commensurate with many considerations, including the relative importance of safety, safeguards, and security; the magnitude of any hazard involved; the life cycle stage of the facility; the programmatic mission of a facility; the particular characteristics of a facility; and any other relevant factor. 
HNF-SD-WM-CM-016

Rev. 0

September 17, 1997

\section{Life Cycle}

A generic term relating to the entire period of conception, definition, build/acquisition, distribution, operation, decommissioning, and disposal of a product.

\section{Participant}

An organization that is performing tasks in direct support of the TWRS mission. An organization to which the TWRS configuration management program is applicable or that provides support to the TWRS configuration management program.

\section{Performance Measures}

A quantitative measure characterizing a physical or functional attribute relating to the execution of an operation or function. Performance attributes include quantity (how many or how much), quality (how well), coverage (how much area, how far), timeliness (how responsive, how frequent), and readiness (availability, mission/operational readiness). Performance is an attribute for all systems, people, products, and processes including those for development, production, verification, deployment, operations, support, training, and disposal. Thus, supportability parameters, manufacturing process variability, reliability, etc., are all performance measures.

\section{Performance Indicators}

A physical or functional characteristic at which performance can be evaluated and measured determines its affectivity.

\section{Physical Configuration}

The actual physical makeup, location, arrangement, and material condition of a product.

\section{Product}

Any item produced and/or used by TWRS including physical items (e.g., tank waste, procured goods), software, documents, data, or systems, structures, or components (equipment). A configuration item is a subset of products that has been chosen to be controlled.

\section{Safety-significant}

Those requirements and/or products that are necessary to protect off-site; on-site, and facility personnel from nuclear hazards and other hazards.

\section{Structure, System, or Component Grade}

A measure of importance of structures, systems, and components (SSCs) within the facility, based on the most important design requirements applicable to the SSC, that can be used to determine priorities and proper levels of attention and resource allocations. Examples of SSC grades and associated priorities are: (1) safety, (2) environmental, (3) mission, and (4) others. 


\section{Supporting Documents}

An engineering text document that describes, defines, reports, or certifies activities, requirements, procedures, or results of engineering activities that support the onsite missions. Other work may use the supporting documents system of identification, review, release, and change control.

\section{System Engineering}

The systematic approach used by management and engineering to transform technical goals into an optimized, integrated, operational, and physical system that achieves the mission. The iterative technical and management process applied throughout the system life cycle that produces and maintains a well-defined and documented system technical baseline.

\section{Technical Baseline}

The defined and approved physical/functional configuration (requirements and design description) of an SSC or computer software. This includes the scope of work that is developed based on the technical requirements.

\section{Turnover}

A formal criteria for the turnover (design to construction, construction to operations, operations to decommissioning, etc.) of new facilities or new modifications of existing facilities. The effective interface is established early in the design process to ensure needed design products will be provided and turnover is successful.

\section{Vendor Information}

Any type of technical documentation/information submitted by a vendor as part of a procurement.

\section{Waiver}

An approved exemption from a particular requirement of the current approved configuration for a specific case or a specified period of time. Waivers relate to variations after the item has been developed or constructed. Waivers differ from approved engineering changes in that they do not change the current approved configuration. 


\section{DISTRIBUTION SHEET}

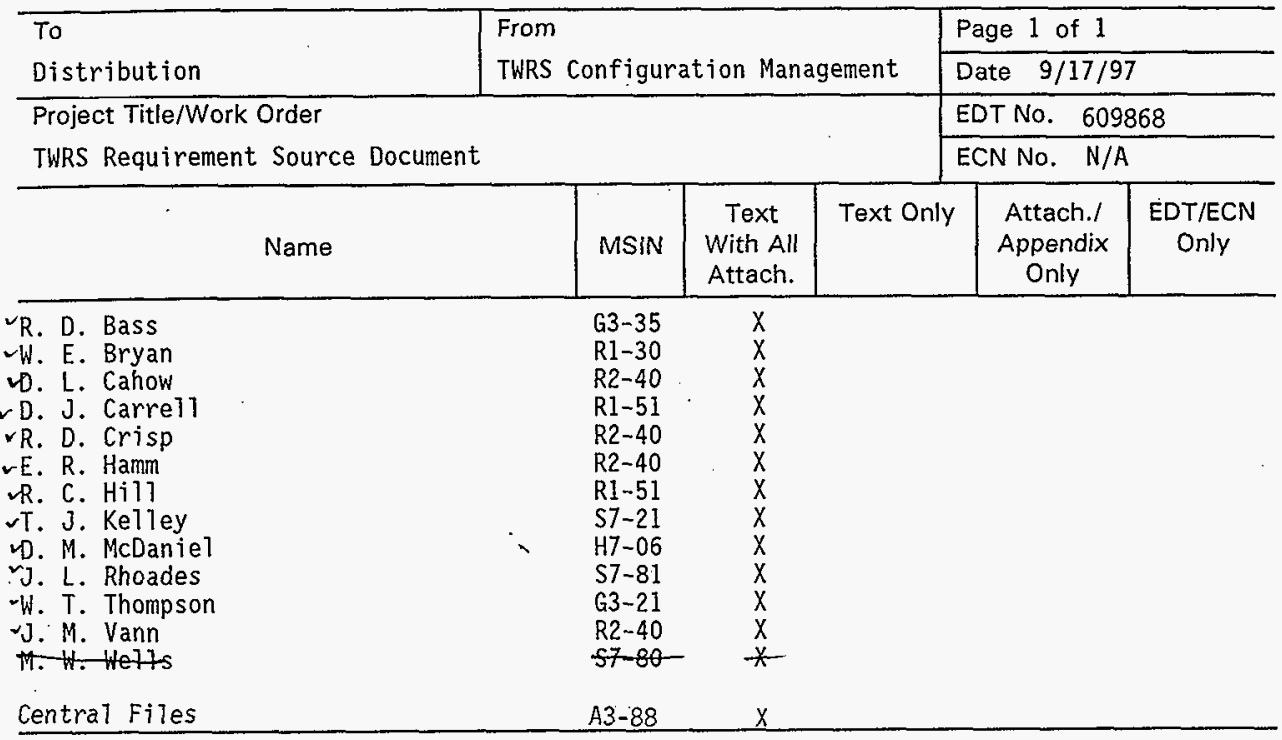

